\title{
PARA UNA FORMALIZACIÓN «TOPOLÓGICA» DE LA SEMÁNTICA
}

\author{
Fernando-M. Pérez Herranz - Antonio J. López Cruces \\ (Universidad de Alicante)
}

\section{RESUMEN}

The logical formalization aroused great hopes for the acquisition of the utmost rigour in language studies and has indeed proved to be successful when applied to the study of syntax (Chomsky). Semantics, on the contrary, has resisted the attempts of axiomatization, falling once and again on the psycologisms and subjetivisms which logic was precisely supposed to overcome. New promising ways, have unexpectedly been opened in the field of Topology studies. In his «theory of catastrophes» (TC) a pure geometric-topologic applied to the appearance and stabilization of morphologies, René Thom proposed a framework in which language is included as one form of morphology. Petitot and Wildgen have carried Thom's proposal still further, and tried to construct a theory of meaning. In the present study, rather than give an account of these investigations, Pérez Herranz ${ }^{1}$ and López Cruices ${ }^{2}$ would like to illustrate their application to a piece of literary writing, namely, the poem Car a a cara by Jorge Guillén. The analysis is twofold: on the one hand the traditional kind, and on the other hand the hermeneutic-catastrofist one. The thesis they defend is as follows: they can identify the hierarchy of verbs as presented by TC in a text dating from much earlier than the mentioned theory, which means a text that has not been constructed ad hoc. They hope to demostrate that the verbs in this poem occur according to semantic rather than pragmatic constraints [contraintes], a fact which will put them on the way towards a semantic formalization.

$\S 1$.

Hace ya algunos años la formalización lógica despertó grandes esperanzas sobre la adquisición de rigor en el estudio del lenguaje. Y nadie puede decir, con sensatez, que no haya realizado una aportación enorme, materializándose tanto

\footnotetext{
1 Dactor en Filosofía.

2 Doctor en Filología Románica.
} 
en el software de los ordenadores -relativo a los programas-, como en lo que constituye su soporte físico (electrónico): el hardware. Esto da luz verde para establecer relaciones de isomorfismo entre los Sistemas Formales y las Gramáticas del Lenguaje Ordinario, como ha sido puesto de relieve, por ejemplo, en los trabajos de la linguística chomskyana. ${ }^{3}$

En pocas ocasiones - y dentro de un tiempo tan relativamente corto- una teoría científica ha alcanzado sus límites con tanta nitidez. Esto es lo que ha ocurrido con el proceso de axiomatización y formalización que se inicia a finales del siglo XIX y culmina en 1931 con el teorema de incompletud de Gödel. El teorema de Gödel ha eliminado confusión e intensísimas especulaciones, pues ya sabemos con certeza que, sea cual sea el sistema formal utilizado, existen enunciados verdaderos cuyo valor de verdad no ha sido asignado mediante el procedimiento formalista. Esto en el plano teórico. Mas en el plano técnico de la Informática han aparecido problemas nucleares en el contexto clave de la traducción de unas lenguas a otras (e, incluso, en una misma lengua, tal como pretende el principio de indeterminación de la traducción de Quine ${ }^{4}$ ). Pero las limitaciones internas de los formalismos no atañen a la validez del proceso de formalización. El teorema de Gödel pone de manifiesto que «deducción» y «verdad» (o Sintaxis y Semántica) no coinciden y, por lo tanto, permite investigaciones independientes, sin la exigencia a priori de su identidad. Y si bien la Sintaxis se ha desarrollado plenamente, la Semántica presenta dificultades internas para la formalización. De tal modo que Chomsky, por ejemplo, sólo considera dotada de propiedades generativas a la Sintaxis, dejando la Semántica, que excede la estructura de los autómatas, a cargo de las Ideas Innatas, con una muy ingrata consecuencia: de los límites internos de los formalismos se pasa a una tesis ontológica que sólo sería legítima si hubiera sido fundada en las descripciones formales como ontológicamente determinantes, lo que no es el caso de las Gramáticas Generativas. ${ }^{5}$

Nos encontramos, en consecuencia, con un doble reto: a) Apelando al rigor, proseguir el camino de la formalización, que requerirá de otras vías que las

3 «Desde el punto de vista tecnológico, las relaciones de la lógica con la informática son asimismo fundamentales, en el doble plano estructural y funcional (...) En la confección de los circuitos que integran el «hardware», es decir, la estructura sólida del computador, juega un papel importante el conocimiento del álgebra de Boole. Por lo que respecta al ámbito del «software», que corresponde, por así decir, al plano funcional, los métodos de formalización, canonización y recursión propios de la lógica simbólica —que han servido también de base a la revolución lingüística de Chomsky - significan una valiosa ayuda en la confección de los lenguajes de programación». GARRIDO, M.: Lógica simbólica, ed. Tecnos, Madrid, 1981, p. 355 . Véase también SERRANO, S.: «Lingüística matemática», pp. 389-413.

4 QUINE,W.V.: Palabra y objeto, ed. Labor, Barcelona, 1968, p. 40.

5 Véanse los trabajos reunidos en HARMAN,G. (comp.): Sobre Noam Chomsky: Ensayos críticos, Alianza Editorial, Madrid, 1981. Searle, v. gr., escribe: «El elemento más débil de la gramática de Chomsky es el componente semántico, como él mismo admite repetidamente (...) La revolución de Chomsky es en gran medida una revolución en el estudio de la sintaxis» (pp. 38 y 45). 
recorridas por los logicistas. b) Un control formal de la Semántica. Reto que puede terminar en éxito, pero también en fracaso. Ya porque la empresa desborda nuestras posibilidades, ya por la imposibilidad misma de la investigación, al modo de las denominadas por Popper ${ }^{6}$ «proposiciones existenciales denegadas» del tipo: «tal y tal cosa no puede ocurrir». Por ejemplo: «no se puede construir la máquina del movimiento continuo»; 0 «no se puede construir una máquina de movimiento al ciento por ciento»; o, en nuestro caso: «no se puede llevar a cabo una formalización de la Semántica».

En todo caso, aceptar el reto significa que suponemos la formalización ya realizada, pues partimos del hecho mismo de las ciencias (el faktum kantiano) y no de una posición originaria, lo que implica que hemos de criticar teorías o verdades ya constituidas. Por eso, nuestro primer punto crítico será la generatividad de la que hacen gala los lenguajes formales.

$\S 2$.

Ocurre que la investigación lingüística en nuestro siglo ha estado dominada por Saussure, que echó las bases para el estudio científico del lenguaje. Pero, como en todo trabajo pionero, no debemos confundir el muy fértil planteamiento saussuriano con algunas de sus tesis, tan criticables como cualesquiera otras. La afirmación del carácter «arbitrario» del signo, que ha sido aceptada por tantos lingüistas como un hecho evidente, es una cuestión presente en nuestra tradición desde, al menos, los sofistas (Hermógenes la defiende en el Cratilo platónico). Tal tesis comporta una dualidad de difícil resolución: ¿Cómo realizar el vínculo entre Significado / Significante? Para evitar la conclusión psicologista, en la que cae el propio Saussure, la Lógica aquí desempeñó un papel muy relevante, porque permite construir un modelo muy refinado para los signos. Con el fin de evitar, por una parte, toda referencia al verbalismo, la ambigüedad, las tautologías... de los lenguajes naturales, y, por otra, la teducción psicologista, se recurrió a formalismos fuertes - con sus axiomas, sus reglas de formación de expresiones bien formadas, sus reglas de transformación, etc.-, que renuncian al concepto de significación denotativa.

Si la Semántica, desde una perspectiva general, establece el conjunto de reglas semióticas que determinan en qué condiciones son aplicables los signos a los objetos o a las situaciones del mundo, la Semántica Lógica establece las reglas desde el punto de vista de la verdad, que, no sin sorpresa, permite razonar sobre los signos directamente de manera independiente de las cosas tras haber definido las condiciones de verdad: recuérdese el método de las Tablas Veritativas, que asigna valores de verdad a cada proposición, de donde resulta que el valor

$6 \quad$ POPPER,K.: La lógica de la investigación científica, sec. 15. ed. Tecnos, Madrid, 1962. 
total de la expresión es función de los valores de las proposiciones tomadas individualmente?

Ciertamente que estos desarrollos en matemáticas y, más en concreto, en sus aplicaciones a los ordenadores, han sido muy eficaces, debido, fundamentalmente, a una de sus propiedades específicas: la recursividad. Los lenguajes formales se dice que son recursivos si podemos aplicar las reglas del sistema a las expresiones que se han obtenido con esas mismas reglas. La imagen más intuitiva de esta propiedad es, seguramente, aquélla de las muñecas rusas que van dentro de otras muñecas rusas, o la de los paréntesis dentro de paréntesis. Esto significa que permiten ejercer la acción de las reglas sobre las fórmulas ulteriores, mejorándolas, generalizándolas, reordenándolas y... extendiéndolas. Pero, resulta que no hay ninguna restricción en lo que se refiere a la longitud de las frases.

a) Nos encontramos aquí con una primera sorpresa. Pues, ¿por qué utilizar un modelo de recursividad cuasi-infinita, cuando et lenguaje natural pone límites enseguida a la generatividad ${ }^{8}$ ¿No es fenómeno corriente que las frases deben recomenzar una y otra vez cada unos pocos segmentos lingüísticos? Toda frase está limitada. Si esta característica es universal, para todas las lenguas, el modelo generativo parece, en principio, desorbitado para el fenómeno linguístico sobre el que se aplica.

(b) Además, tanto los lógicos como los lingüistas parecen olvidar que el significado (la conceptualización) se asocia al mundo referencial, que posee un espacio multi-dimensional, de dimensión tres o cuatro, mientras que el significante (la enunciación) posee un espacio lineal, uni-dimensional. Efectivamente, este hecho tan relevante se olvida a menudo, porque se recurre a una transformación psicologista que traduce de manera intuitiva el significante. Pero, si queremos evitar una teoría psicologicista del signo, podemos seguir otra vía para controlar estas proyecciones entre espacios (que los matemáticos llaman variedades). ${ }^{9}$

T Es Frege quien primero habla del proceso de composicionalidad. Véase Escritos lógicosemánticos, ed. Tecnos, Madrid, 1974, p. 39.

\& Thom habla de la fatiga del lenguaje: «Or, même chez les auteurs les plus extravagantes à cet égard, comme Proust, il y a une borne supérieur à la longueur des phrases. Tout tentative d'explication de la forme linguistique doit nécessairement comporter un aspect dynamique, génétique, qui rend compte, pour une phrase donnée, de la totalité des opérations syntactiques qui en permettent la genèse en tant que processus neuro-physiologiques, et en assurent la correction grammaticale. Or, la totalité de ces processus est assujettie à des contraintes mnémoniques ou psychophysiologiques, qui en limitent le nombre et la disposition relative. Autrement dit, tout se passe comme si un axiome se FATIGUE lorsqu' on s'en sert». THOM,R.: Modèles mathématiques de la morphogenèse, ed. Chistian Bourgois, París, 1980, p. 195 (En abreviatura, MMM).

Quien quiera divertirse a la vez que fatigarse recursivamente, puede recordar aquel juego infantil de «palabras encadenadas». Las reglas son muy sencillas: (I) Cada jugador, altemativamente, ha de ir mencionando una palabra que se acumula formando una frase. (II) La mención de cada palabra ha de hacerse incluyéndola en la frase que se va formando. La fatiga se notará a poco de empezar: $¿$ diez, veinte..., cien palabras? V. gr.: Jugador A: «en». Jugador B: «en el». A: «en el patio». B: «y en el patio». \&c. Enseguida hay que volver a empezar. 
Tal es el arranque mismo de la crítica que hace el topólogo Thom a lógicos y generativistas. Desarrollemos este punto tan esencial y tan olvidado.

\section{$\S 3$.}

Propiedades de los sistemas uni-dimensionales.- La crítica de Thom va dirigida contra la tesis del apartado a) la generatividad libre de los lenguajes formales, pues «es la autolimitación de las capacidades generativas de la sintaxis lo que pide explicación». ${ }^{10}$ Por esta razón, las lenguas naturales no son axiomatizables, puesto que su fundamento ha de encontrarse en la (auto-) regulación biológica y física, i. e., en la estabilidad de los organismos. Distinguimos, entonces, entre generatividad y operatividad. La Generatividad permite construir fórmulas tan largas y complejas que pudieran imposibilitar su interpretación intuitiva; además limita los resultados, ya que no pueden ir más allá de una geometría uni o bi-dimensional. De esta manera, tanto los términos como los resultados generados mediante el uso de las reglas de transformación permanecen en el mismo plano espacial. La Operatividad, que se lleva a cabo, por lo general, en el espacio tri o tetra-dimensional, queda proyectada en el espacio uni o bi-dimensional. No tiene nada de extravagante que la Lógica haya nacido junto a la Geometría; pues la Lógica ha permitido organizar la representación (demostración) de la Geometría en un lenguaje intermedio entre las morfologías tri-dimensionales y el lenguaje natural, uni-dimensional. Ésta fue la gran labor de Euclides: organizar lógico-operatorio-algebraicamente (uni-dimensional) la Geometría (tri-dimensional).

Pero los signos matemáticos «desplegados» en un espacio uni-dimensional constituyen el propio contenido material de ese espacio y llevan ya incluidas estructuras lógicas particulares. El análisis gnoseológico de estas entidades materiales que son los signos no ha sido aclarado suficientemente - creemoshasta el artículo «Operaciones autoformantes y heteroformantes» de Gustavo Bueno. ${ }^{11}$ Las operaciones lógicas —diremos- son autoformantes. Amparándose en la materialidad física de los signos lógicos, y, recurriendo a una justificación ontológica, el materialismo formalista no considera la Lógica ni como un reflejo del Mundo — al modo de la metafísica - ni de la matemática —al modo

9 La distinción entre espacios uni y n-dimensionales es fundamental en nuestra investigación. El arranque de esta problemática se inicia en Aristóteles. Para la relación Aristóteles y la TC, nos remitimos a Pinchard: «Anexo» a THOM, R.: Esbozo de una Semiofísica. Física aristotélica y teoría de las catástrofes, ed. Gedisa, Barcelona, 1990.

10 THOM, R.: $M M M$, pp. 164 y 292.

11 En El Basilisco, n 7 y 8, 1979. También PÉREZ HERRANZ, F.: «La fundamentación lógica y la teoría de las catástrofes», en el Congreso sobre "Categorías e Inteligibilidad global, San Sebastián, abril, 1993. La distinción de G. Bueno es, nos parece, de cuño kantiano. Kant distingue entre signos in abstracto, carentes de conexión interna con su significado, y signos in concreto, que pueden abandonarse a la lógica misma de su formalismo. 
formalista-, sino como «un artefacto construido en el plano bidimensional del papel o de la pizarra (...) La Lógica formal no será, así, tanto el «reflejo mental» de la Lógica Universal, o la «trama a priori» del Mundo, cuanto la construcción de un campo cerrado en un espacio de dos dimensiones (las «leyes» en dirección Izquierda / Derecha; las «reglas» en la dirección Arriba / Abajo, y mantenido dentro de unos márgenes de temperatura precisos». Se requiere, por tanto, una teoría del símbolo diferente al tópico de ser un nombre que sustituye a una entidad, ya física, ya ideal. Diremos que un símbolo es autonímico o autónimo si el significado es causa del significante, la característica de los términos autorreferentes; y diremos que un símbolo es tautogórico si el significante es causa del significado, la característica de los signum sui, los signos religiosos o míticos que «causan un efecto». Los símbolos autogóricos, son, a la vez, autonímicos y tautogóricos.

Interpretar los símbolos como autogóricos es aquí lo decisivo. Los símbolos no son algo puramente formal, vacio, sino que en ellos se reconoce toda la estructura geométrica (ordenaciones, permutaciones, derecha, izquierda) que en su propia realidad de significantes debe ir implicada. V. gr., el número $(1+1+1)$ se representa por una tríada; las letras variables $(A, B, C)$ son ya clases, etc.

$\S 4$.

Ciertamente, el lenguaje es algo material ${ }^{12}$, los sonidos se propagan, etc. De ahí la necesidad de incluir la Fonética o la Fonología como partes de la Gramática. Una consecuencia de esta tesis es que esos sonidos al combinarse entre sí mediante reglas específicas producen cadenas uni-dimensionales, estudiadas por la Sintaxis. Ahora bien, estas cadenas no son nada en sí mismas (excepto en el caso del estudio de esos signos qua tale signos, que es el objeto del álgebra y, en cuanto tales, se someten a las operaciones autoformantes), sino el medio a partir del cual se pretende dar cuenta de conceptos o ideas. Este nivel, el semántico, desborda todo el interés de las formalizaciones sintácticas.

(i) La teoría clásica que mejor acogida ha tenido ha sido la Teoría de Modelos, TM, (en la versión de Tarski ${ }^{13}$, para distinguirla de la teoría clásica de

12 Como ya advirtiera, sorprendido, Ortega: «La más somera oteada sobre la evolución de la gramática debía haber llevado a esta advertencia. La gramática comienza analizando el fenómeno verbal en cuanto que éste es palabra oída. En milenios no dio un paso esencial nuevo esta primera gramática, hasta que en el siglo XIX aprendió a hacerse lo bastante humilde para reparar en este trivialísimo hecho: que la palabra, antes de ser sonido y ser oída, tiene que ser pronunciada; que es, por tanto, antes movimiento muscular: laríngeo, bucal y nasal. Cuando el sonido verbal fue retrotraído a su génesis - como sistema de hábitos articulatorios musculares - nació la fonética y, con ella, el prodigio de rigor que es la nueva gramática. Pero en esta idea de la lengua como musculación,...». ORTEGA y GASSET, J.: Obras completas, tomo 9, pp. 760-761. 
Aristóteles) que comporta la tesis de que las matemáticas y la lógica son un lenguaje, y que el sistema sintáctico es manipulable mediante diversas operaciones sometidas a reglas. La TM define la verdad (que es la categoría central de la Semántica) como una correspondencia (en lenguaje técnico, un isomorfismo) entre las estructuras lingüísticas y la Realidad. Dice Tarski: «Una oración es verdadera si designa un estado de cosas existente». Ahora bien, como el número de cosas que hay en el mundo es, por principio, indefinido (e incluso, infinito), - por saberlo, Aristóteles se vio obligado a comenzar su tratado de las Categorias mediante la teoría de la homonimia - el número de nombres isomórficos debería serlo también, lo que es absurdo; entonces el lenguaje no puede ser un conjunto infinito de nombres, tiene que ajustarse a un vocabulario finito y a un conjunto de reglas finitas, tal como propuso Hilbert. Pero ser conscientes de esta situación significa que el concepto de «verdad» ha de estar referido siempre a un lenguaje, lo que obliga a especificar sus reglas y, paradójicamente, una teoría de la verdad. volcada en los hechos realiza su análisis en el campo del lenguaje, para impedir, pongamos por caso, la formación de paradojas (mediante el expediente de distinguir el lenguaje-objeto y el metalenguaje), usando reglas recursivas que permitan construir series infinitas, esto es, aplicaciones a situaciones nuevas, y flexibilizar las posibilidades de formación de frases según los operadores lógicos: $\forall, \exists, \mathbf{\Lambda}, \mathbf{V}, \neg \ldots$

Lo curioso es que, al definir el predicado semántico de «verdad», Tarski utilizó el concepto de satisfacibilidad. Pero, ¿respecto de qué se define ésta? La primera intención de Tarski fue el «Mundo». Al desarrollar una teoría de la verdad como correspondencia, Tarski se ve en la obligación de identificar el Mundo como un trasunto de la Teoría de Conjuntos. Una teoría de la verdad como correspondencia nos conduce, paradójicamente, por caminos poco o nada ontológicos: (a) Por un lado, la tarea de la filosofía se limitará a establecer las condiciones lógico-formales de lo que puede ser dicho con sentido, identificando análisis metalingüístico con epistemología. (b) Por otro lado, el «Mundo» es reemplazado sistemáticamente por la teoría conjuntista.

La consecuencia de este planteamiento es que elimina toda preocupación fenomenológico-ontológica, i.e., la relación lenguaje / mundo se reemplaza por la relación metalenguaje / lenguaje-objeto. Pero entonces se ha de suponer la tesis de que la realidad es expresada por el lenguaje, supuesto que escapa a los controles de la analiticidad. Las dificultades ontológicas obligarían a Tarski a reemplazar el Mundo por la Teoría de Conjuntos, que es ya la posición común

13 Véase, v. gr., cómo Popper acepta la teoría de modelos de Tarski: «A la vez, la teoría de Tarski rehabilita y reelabora también algunas de las críticas clásicas a esta teoría de la correspondencia, pues indica hasta qué punto están en lo cierto quienes sospechan que la teoría de la correspondencia es paradójica. Esta última parte la resuelve esencialmente la teoría de Tarski, según la cual la semántica $\left(L_{1}\right)$ de un lenguaje objeto $\left(L_{0}\right) \ldots$ ha de ser esencialmente más rica (de orden superior) que el lenguaje objeto...». POPPER, K.: La lógica de la investigación científica, ed. Tecnos, Madrid, 1973 , p. 292. 
entre los lógicos. La Teoría de Modelos no es más que una aplicación de la Teoría de Conjuntos sobre sí misma: «Los «lenguajes» de que habla la Teoría de Modelos son sistemas matemáticos. Y las cosas (grupos, órdenes, espacios, sistemas de Peano...) representadas en esos lenguajes son también sistemas matemáticos con otros sistemas matemáticos».14

(ii) Pero rechazar la formalización algebraica nos conduce a una vuelta a la introspección, a la psicologización inaccesible al análisis objetivo o a la fenomenología husserliana, que pretende describir las esencias de las vivencias de la conciencia pura, a la cotidianeidad, a la intuición, al sentido común, etc. Mas, de seguir cualquiera de estos caminos, habría que preguntarse cómo representamos el significado. $\mathrm{Y}$ esto exige algo que se olvida a menudo: el marco espacio-temporal en donde se realiza la representación. Así que nos enfrentamos a tres posibilidades: (a) Recurrir al «espacio» de la Física clásica. (b) Recurrir al «espacio» de nuestra experiencia. (c) Reformular desde un espacio que posea otras características.

No es éste el momento de hacer una crítica a las dos primeras. Bástenos mencionar el atomismo ontológico de la primera y el espontaneísmo y la especulación de la segunda. La aportación de Thom - que contesta al apartado b) - ha sido proponer a los lingüistas un concepto de espacio no usual entre ellos, un concepto de espacio-tiempo que es operatorio en la Dinámica de Sistemas: el espacio-fibrado. ${ }^{15}$ En la Física clásica, los estados de un sistema son descritos por puntos de un espacio de fases $\mathbf{M}$, y su evolución por un campo de vectores $\mathbf{X}$ en $\mathbf{M}$. Pero no es posible utilizar este modelo en lingüística o en biología, cuyos estados poseen una complejidad irreducible al punto. Los objetos fluidos, pongamos por caso, exigen introducir variedades de dimensión infinita, para los que el campo es muy difícil, si no imposible, de explicitar o integrar. Este campo está siendo alterado continuamente por perturbaciones difíciles de precisar o desconocidas. El concepto de «fibración» permite explicitar un axioma aristotélico olvidado: «Lo que es primero por naturaleza es posterior por generación» (Fis., 261² 14) En apretadísimo resumen lo explicaríamos así: la homogeneidad inicial —el huevo, v. gr.- crea por bifurcac ones sucesivas, atractores que necesitan nuevos parámetros que estabilicen la situación, por despliegues de las sucesivas bifurcaciones, hasta llegar al estado final ( $\tau \varepsilon \lambda \varepsilon i o v)$

14 MOSTERÍN, J.: «Prólogo» a MANZANO, M.: Teoría de modelos, Alianza ed., Madrid, 1989 , p. 16. Por otra parte, Davidson, en la línea iniciada por Frege de que la comprensión del significado de una oración consiste en comprender las condiciones veritativas, ha construido una teoría muy refinada que, sin embargo, ha merecido críticas muy severas. Pero no podemos detenernos ahora en este autor.

15 THOM, R.: Semiofísica, op. cit., pp.. 219-221. Cfr. también, CHÂTELET, G.: «Le potential demoniaque» en Logos y Théorie des catastrophes, ed. Patiño, Genève, 1988, pp. 199-214. PÉREZ HERRANZ, F.: «El concepto de «lugar natural» y el espacio fibrado» en BUSTOS, E., y otros (eds): Actas dell Congreso de la Sociedad de Lógica, Metodolog ía y Filosofia de la Ciencia, Madrid, 1993, pp. 481-484. 
con sus contornos y perfiles, esto es, su forma espacial ( $\mu \circ \rho \phi \varepsilon)$.

(iii) Hemos de tener presente en el comienzo mismo de nuestra exposición que la Lógica (algebraica, más que matemática) no es el único instrumento de formalización. La lógica posee un campo limitado a espacios uni-dimensionales.

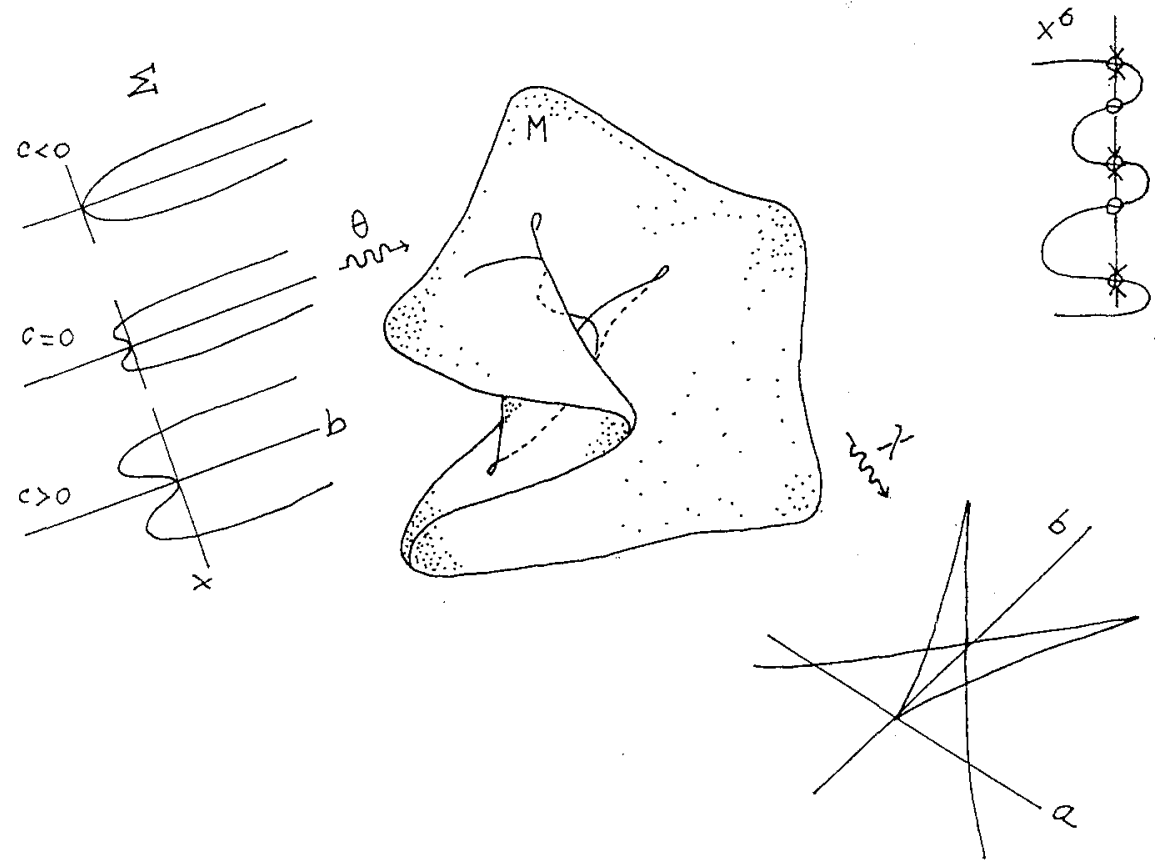

Mas a partir del siglo XIX, de las geometrías no euclidianas, la geometría y la topología permiten desarrollar lo que podemos llamar proyecciones de espacios $n$-dimensionales -espacios que no pueden, en general, visualizarse, en otros espacios-, investigación que se inicia con los trabajos de Hopf: proyecciones de una esfera sobre otra de dimensión inferior. En esta línea, Whitney mostró que en las proyecciones de una superficie sobre un plano sólo se encuentran dos tipos de singularidades: el pliegue: y la cúspide: >. René Thom ha clasificado todos los tipos de bifurcaciones para sistemas de gradiente dependiente de cuatro parámetros, i. e., que las rupturas y fraccionamientos de las morfologías empíricas responden a las ya famosas siete «catástrofes elementales»: pliegue, cúspide, cola de milano, mariposa, umbílicas hiperbólica, elíptica y parabólica. En la figura 1 damos las proyecciones de la catástrofe mariposa, en donde $\mathrm{M}$ es una variedad llamada de catástrofe o superficie de equilibrio; $\chi$ es una aplicación de la superficie de equilibrio en el plano de los parámetros de control $\mathrm{C}$, de 
coordenadas $(\mathrm{a}, \mathrm{b})$. Y $\theta$ es una aplicación del plano producto de las variables de estado (S) y de las de control (C), de coordenadas (x,b). $\Sigma$ es el conjunto de singularidades o puntos críticos $\mathrm{M}$ de $\chi ; \chi(\Sigma)$ en $\mathrm{C}$ es el conjunto de bifurcación $\mathrm{K}$, conjunto en el que el número y naturaleza de los puntos críticos cambian.

(i) Potencial: $V_{(a, b, c, d)}=1 / 6 x^{6}+1 / 4 d x^{4}+1 / 3 c x^{3}+1 / 2 b x^{2}$. El germen $x^{6}$ presenta en el origen un mínimo degenerado obtenido por colapso de 5 puntos críticos, 3 mínimos y 2 máximos. El despliegue entonces es el resultado de hacer variar la altura de los máximos y mínimos de todas las maneras posibles.

(ii) El espacio de fase es $\mathrm{R}^{5}$, que no se puede dibujar.

(iii) Variedad Catástrofe: $V_{(a, b, c, d)}^{\prime}=x^{5}+d x^{3}+c x^{2+} b x+a=M$

Como no podemos representar $\mathrm{M}$ directamente, trataremos de hallar algunos apilamientos a partir de las singularidades del conjunto $\mathrm{K}$.

(iv) El conjunto de las singularidades:

$$
\begin{aligned}
& V^{\prime \prime},{ }^{(a, b, c)}=5 x^{4}+3 d x^{2}+b x ; \\
& \left.V^{\prime \prime}\right)^{(a, b, c, d, d)}=20 x^{3}+6 d x
\end{aligned}
$$

(v) Conjunto de Bifurcación: Para visualizar $\mathrm{K}$ vamos buscando las proyecciones sobre los distintos planos de control que pueden aislarse:(a,b), $(\mathrm{a}, \mathrm{c}),(\mathrm{b}, \mathrm{c})$. Para ello se toman las ecuaciones:

$$
\begin{aligned}
K_{(a, b, c)}= & V^{\prime}=x^{5}+d x^{3}+c x^{2}+b x+a \\
& V^{\prime \prime}=5 x^{4}+3 d x^{2}+2 c x+b \\
& V^{\prime \prime \prime}=20 x^{3}+6 d x+2 c
\end{aligned}
$$

de donde la representación paramétrica: $c=-10 \mathrm{x}^{3}-3 \mathrm{dx} ; \mathrm{b}=15 \mathrm{x}^{4}+3 \mathrm{dx} \mathrm{x}^{2} ; \mathrm{a}=-$ $6 x^{5}$.

Si ahora damos un valor a d: mayor, menor o igual a 0 , se van dibujando sobre los planos de control: $(a, b),(a, c),(b, c)$ como se indica en la figura 1 . Los conflictos de régimen asociados a esta singularidad se encuentran en el interior de la curva mariposa, donde la variedad catástrofe $V^{\prime}{ }_{(a, b, c, d, x)}$ tiene cinco raíces reales. Puede haber, pues, conflicto entre tres mínimos.

¿En qué campo se aplica, propiamente, una teoría de estas características? En principio puede considerarse como una teoría geométrico-topológica pura. Pero, como ya es tópico, las investigaciones matemáticas muy abstractas como la lógica de Boole o la teoría de matrices de Heisenberg-, encuentran aplicaciones en el dominio de la práctica —en los ordenadores o en las centrales nucleares-. Es cierto que, también por lo general, estas aplicaciones encuentran su campo científico apropiado en la física. Pues bien, lo relevante de la investigación de Thom es que ha aplicado esta teoría en el campo de la biología y - lo que suele ser más sorprendente - en la lingüística. ¿Cómo podemos entender esto?

$\S 5$. 
El que Thom haya incidido en la biología no hay que echarlo en saco roto. Pues la biología le conduce hasta la lingüística por mediación de la Etología.

En epistemología, Thom es inmanentista: supone que los organismos (los dotados de un sistema neurofisiológico) poseen mecanismos cerebrales que simulan las leyes de la mecánica. ${ }^{16}$ Esta posición exige un paso intermedio entre el lenguaje y la biología, que no es otro que el de la Etología. El lenguaje entendido como uno más - aunque con consecuencias decisivas- entre los mecanismos de regulación de los seres vivos: la nutrición, la reproducción, el miedo... En la discusión filosófica central sobre si el lenguaje es una característica propiamente humana, hallamos dos posturas básicas: a) la defendida por las tradiciones aristotélica - que define al hombre como el ser que posee logos, palabra, lenguaje - y cartesiana - que separa la res cogitans de la res extensab) la defendida por las tradiciones epicúrea —que enseñaba que los significantes no proceden arbitrariamente, sino que son producidos por el medio corpóreo ${ }^{17}$ y empirista — «Cualquier teoría por la que explicamos las operaciones del entendimiento, o el origen y la conexión de las pasiones del hombre, adquirirá autoridad adicional si encontramos que la misma teoría es necesaria para explicar los mismos fenómenos en todos los demás animales» (Hume) —, según las cuales el lenguaje es una característica compartida por el hombre con otros seres $^{18}$. Thom apuesta inequívocamente por la segunda tradición: «La capacidad manifestada por los primates superiores de adquirir casi espontáneamente en los lenguajes de signos (...) ha sorprendido a los teóricos que ven en la organización sintáctica de nuestras lenguas un carácter específicamente humano. Para quienes piensan —como quien esto escribe- que los mecanismos sintácticos más fundamentales son copias que simulan (definidas en un espacio abstracto) grandes funciones reguladoras de la biología (predación, relación sexual), la cosa es menos sorprendente...». ${ }^{19}$

En esta línea, el lenguaje, lejos de ser meramente flatus vocis, tendrá un significado propio y las palabras se referirán a las cosas, porque, si no, no hablaríamos del mundo, sino del lenguaje, y el hombre es un organismo más con todas las necesidades de autorregulación, estabilidad, capacidad de reproducción, etc. Nos topamos con unas estructuras propias de la especie, que tenemos que estudiar en la rúbrica de los «Universales Linguísticos», al identificar lenguaje

16 THOM, R.: $M M M$, p. 197.

17 «Los nombres, por tanto, no fueron creados, en principio, por convención, sino que las diversas naturalezas de los hombres, experimentando según cada pueblo afecciones particulares y particulares representaciones, hacían salir de una manera, particular también, el aire emítido bajo el impulso de cada una de estas afecciones y representaciones, de acuerdo, tal vez a la naturaleza de los lugares que habitaban». Epístola a Heródoto, 75.

18 HUME, D.: Investigación sobre el entendimiento humano, sección 9.

19 THOM, R.: $M M M$, p. 298. (La traducción es nuestra). 
y concepto, y proponer una teoría de las categorías de manera natural. La estructura de la frase «refleja» según el método de la proyección geométrica, no de la teoría pavloviana del reflejo, la estructura dinámica de las catástrofes externas.

$\S 6$.

De esta manera se va construyendo un lenguaje teórico que rechaza los formalismos generativos y que parte de unas matemáticas cualitativas en el sentido de los Sistemas Dinámicos. Se utilizarán conceptos de este tenor: Estabilización de sistemas naturales o artificiales; Sistemas Regulados: la estabilidad de una «palabra»; Atractores, etc. Thom muestra que el desglose lingüístico de un proceso espacio-temporal puede explicarse por la teoría de la Estabilidad Estructural. Una frase nuclear sería esencialmente el resultado de un conflicto entre regímenes locales (actantes: sujeto, objeto directo, destinatario...) que se disputan en un campo (circunstantes: tiempo, lugar, instrumento, modo... y localizadores: adverbios, pronombres...) un dominio del espacio-tiempo, $\mathrm{R}^{4}$. De esta manera, el número de morfologías es relativamente pequeño. Esto - dice Thom- permite clasificar (de un modo más fino que la teoría de la valencia de Tesnière) los verbos. Las estructuras algebraico-topológicas que regulan las posibilidades de entrar en conflicto los actantes son llamadas por Thom el «logos» del sistema. La Sintaxis no puede quedar independizada de la Semántica, al ser ésta la que le impone sus contenidos y sus límites. Como dice Thom: «En cambio, la combinación, la sintaxis de las palabras no es arbitraria, pues está impuesta por las interacciones semánticas entre los conceptos». ${ }^{20}$ Thom ha propuesto las catástrofes elementales - las maneras de establecer las singularidades - como los logoi, modelos, arquetipos, o universales de las morfologías del significado. ${ }^{21} \mathrm{~V}$. gr.:

—Despliegue «Cero»: la semántica de términos-masa: oro, agua..., que pueden ser divididos sin cambiar su identidad; procesos continuos sin accidentes: ser, existir, vivir, estar... en un dominio ilimitado; persistir, en el sentido de cualidades inalienables, que constituyen la identidad de un objeto; tener, poseer un objeto, de manera estable, estar situado en... Se expresa mediante verbos cero-valentes en terminología de Tesnière. V. gr.: «El niño tiene sed», «El bebé duerme». - La catástrofe o singularidad pliegue: las morfologías del nacimiento y de la muerte; la semántica de los procesos de aparición o desaparición súbita. Desde un punto de vista espacial: frontera y extremo. Desde un punto de vista temporal: empezar y terminar... Es el arquetipo de las fronteras, de los bordes: entrar, salir, abandonar...; perder una cualidad estable: casarse, morir... (no hay

20 THOM, R.: Stabilité Structurelle et morphogénèse, InterEditions, Pris, 1977, p. 310.

21 POTTIER, en su Semántica general, ed. Gredos, Madrid, 1993, ha acogido y utilizado la clasificación de Thom como una teoría plenamente válida. 
gradación en el paso de un estado a otro), ir a/marcharse, llegar a/salir o arrancar, alargar/dejar, perder/encontrar, aparecer/desaparecer. Se expresa mediante verbos neutros uni-valentes, con sujeto pero sin complemento). V. gr.: «El día acaba», «Pedro muere».

- La catástrofe cúspide: las morfologías de la reunión y de la separación; la morfología de captura. Espacialmente: frunce, falla... Temporalmente: separar, unir, capturar, generar, cambiar... Es el arquetipo de las ideas semánticas de reunión y separación y de la flecha del tiempo. Cambio de lugar: A se mueve de $M_{1}$ a $M_{2}$; camina de...a...; conduce de...a...; viaja de...a...., etc. A pasa de un estado cualitativo a otro. Hay una organización bipolar cualitativa de los cambios: vigilia/sueño, bueno/malo, fuerte/débil, grande/pequeño, activo/ pasivo, nervioso/calmo; cambios en las actividades ejercidas: descanso/tensión, guerra/paz, ataque/huida, gas/líquido (no tiene en cuenta el objeto que cambia, pues este arquetipo sólo posee dos atractores); dar, entregar, recibir... Ésta es la interpretación más usada por Thom, la fundamental en biología: capturalemisión. A veces tiene un carácter repetitivo, cíclico. Entonces es el arquetipo del golpear rítmico, del diapasón, como caso límite: caminar, correr, danzar...; alargar/tender (con el arma, con el Instrumento). Se expresa mediante la frase transitiva clásica: Sujeto-Verbo-Objeto. El Sujeto es el actante que sobrevive a la catástrofe y triunfa. El Objeto sufre la catástrofe y puede llegar a perecer (verbos bivalentes: sujeto más complemento directo). V. gr.: «Eva come la manzana del árbol del bien y del mal», «El gato atrapa al ratón», «Jaime lanza una piedra».

- La catástrofe cola de milano: la morfología del suicidio. Las singularidades físicas tienen que ver con un régimen condenado a desaparecer, pero que, antes de que ello ocurra, salta a otro régimen metaestable que también desaparece. Espacialmente: hendidura, surco... Temporalmente: rasgar, aserrar... Es el arquetipo del «casi», del «estar a punto de algo». En biología, el «suicidio»: algo que se autodestruye. La acción de golpear, hendir. V. gr: «El traidor se suicidó», «Lo tengo en la punta de la lengua».

- La catástrofe mariposa: la morfología del don. La semántica de la acción de «dar» algo a alguien, al modo de la clásica morfología: Fuente-MensajeroReceptor. Espacialmente: copo, bolsillo, escama... Temporalmente: llenar, vaciar, dar, recibir... Es el arquetipo del paso a un efecto por mediación de algo. Ir de un sitio a otro pasando por otro. La secuencia: joven-maduro-anciano, buenoindiferente-malo, verdadero-indefinido-falso... El paso se puede realizar por mediación de zonas diferentes: El cielo se oscurece y se torna negro. Esta transición puede tener dos direcciones, con cambio del mediador:

$$
\begin{aligned}
& \text { guerra } \rightarrow \rightarrow \text { armisticio } \rightarrow \rightarrow \text { paz } \\
& \text { guerra } \leftarrow \leftarrow \text { movilización } \leftarrow \text { paz }
\end{aligned}
$$


Esta es una interpretación central en Thom. Combina el arquetipo de emisión con el de captura. Se puede entender, por consiguiente, como el arquetipo de transferencia: «Eva da una manzana a Adán». Es el arquetipo de la acción indirecta. El segundo agente no sería sino un medio auxiliar. Creemos que no se le ha sacado todo su partido al asociarla con la «mitad» del famoso pasaje de Hegel del «amo y el esclavo». «El granjero golpea a su jumento con un garrote». Se expresa por verbos tri-valentes (que poseen Sujeto, Objeto y Destinatario). V. gr.: «Eva da una manzana a Adán», «Viajó de Huelva al Caribe».

- La umbílica elíptica: la semántica de los estados de tensión; del sexo masculino. Espacialmente: aguja, pelo,... Temporalmente: perforar, rellenar, pinchar... Es el arquetipo del mensajero. Se parte de cuatro actantes: el Sujeto, que emite un Mensaje a través de un Mensajero a un Destinatario. El Mensajero va junto al Sujeto, que se escinde y emite un actante capturado por el propio Mensajero. El estado conseguido es metaestable, por lo que se dirige al Destinatario, que captura al actante y libera al Mensajero, que ya puede alejarse. V. gr.: «Juan envía una carta por correo a Pedro», «Julián va de Vigo a Cádiz pasando por Sevilla».

- La umbílica hiperbólica: la semántica de los estados de relajamiento; del sexo femenino. Espacialmente: cresta, arco... Temporalmente: colapsar, englobar... Es el arquetipo de captura, «prehensión». Hay tres actantes: un Sujeto, un Objeto y un Instrumento. Los dos últimos forman un complejo metaestable, que, al aproximarse al Sujeto, se deshace y el Sujeto captura al Objeto. V. gr.: «Me pongo el sombrero».

- La umbílica parabólica es la semántica más compleja. Espacialmente: chorro, boca... Temporalmente: brotar un chorro, abrir y cerrar, horadar, cortar pellizcar, tomar, arrojar... Es el arquetipo de escisión. Un actante, el Sujeto, con ayuda de un Instrumento, provoca una excisión en el otro actante, el Objeto. La parte escindida es capturada por el Instrumento. Esta morfología es muy rica y muy común en el mundo. Así los verbos: cortar, resolver, dilucidar, zanjar, extraer, desgarrar, arrancar, hundir, horadar, agujerear... La acción de cortar en trozos antes de comer es el ejemplo más significativo de esta singularidad. V. gr.: «Me ha arrebatado el dinero bajo la amenaza de una pistola».

$\$ 7$.

Pues bien, Petitot y Wildgen ${ }^{22}$ han llevado más lejos estas insinuaciones de Thom. Pero más que presentar sus teorías quisiéramos dar un ejemplo sobre un

22 PETITOT, J.: Les catastrophes de la parole, ed. Maloine, y Morphogenése du sens, PUF, ambas en Paris, 1985; WILDGEN, W.: «Archetypal Dynamics in Word Semantics: An application of Catastrophe Theory» en Words, Worlds and Contexts, ed. Eikmeyer,H.J. y Reiser,H., New Jork, 1981, y Catastrophe Theoretic Semantics. An Elaboration and Application of René Thom's theory, ed. Benjamin, ambas en Amsterdam, 1982. 
texto literario para hacer vislumbrar el alcance de las mismas. Nos hemos permitido, entonces, realizar dos análisis paralelos: uno desde el punto de vista de la Semántica Clásica, y otro en el sentido de la Semántica Topológica, siguiendo las recomendaciones de Wildgen: «De mon point de vue la TC forme l' avantgarde d' une analyse géométrique et on verra d'autres techniques de la même famillle apparaître. Il en suit qu' on ne peut pas analyser tout avec la TC, et on ne peut que faire ressortir certains aspects qui furent moins visibles dans l'analyse traditionelle». ${ }^{23} \mathrm{Y}$ nosotros añadiríamos que tiene un interés no sólo formal sino también metodológico y hermenéutico.

\section{ANÁLISIS DEL POEMA «CARA A CARA» DE JORGE GUILLÉN:}

\section{(I) ENFOQUE CLÁSICO.}

El extenso romance Cara a $\operatorname{cara}^{24}$ anuncia la temática y la métrica de tantos poemas de Clamor, libro a partir del cual la poesía de Guillén opta por el romance y el verso suelto frente a las estrofas más usadas anteriormente como la redondilla, la cuarteta, el serventesio, el cuarteto o la décima. De rima asonante o-o y dividido en seis apartados señalados con números romanos, se publicó por primera vez como cierre de la tercera versión de Cántico, la de 1945, editada por Litoral en México y subtitulada ya $F e$ de vida. Es uno de esos diecisiete nuevos poemas mayores, de gran importancia teórica, que resaltan el enorme crecimiento de Cántico desde 1928.

Cara a cara se halla incluido en «Pleno ser, la parte quinta del libro de Guillén - coincidente con la primera, Al aire de tu vuelo, en la común atención al hombre situado en la realidad-, que mira con mayor fuerza a la plenitud del ser y se centra especialmente, con un cierto abandono de las cosas, en la vida del poeta. Si Cántico se abre con Más allá, «explicación de cómo el alma, el cuerpo, la luz y las cosas funcionan en todo el libro», se cierra con Cara a cara, poema que - precedido de una cita de García Lorca: «Lo demás es lo otro: viento triste, / Mientras las hojas huyen en bandadas» ${ }^{25}$ _ «toca ya esas fuerzas desestabilizadoras, que protagonizarán Maremagnum y contra las cuales el poeta

\footnotetext{
23 Carta privada a los autores con fecha 19-10-1993.
}

24 Citamos en adelante por la edición de Cántico, ed. Seix Barral, Barcelona, 1974.

2s Aunque J. M. Rozas y Torres Nebrera circunscriben el poema a la guerra civil española «el libro acaba, ostentosamente mirando hacia Clamor, con el poema Cara a cara sobre la guerra civil, partiendo de la muerte de Lorca, y denunciando la presencia de dioses enemigos y del agresor general» (El grupo poético del 27, I, Madrid, 1980, p. $7 \mathrm{i}$ ), nos parece mejor destacar en él sus valores más universales, tal como hacía J. M. Valverde, en su artículo «Plenitud crítica de la poesía de Jorge Guillén» (Clavileño, 4, 1951): «Finalmente, el poeta se enfrenta con el mal universal, con el dolor mundial, que le sitia, mugiendo como un océano en tomo al faro (...) Y entonces se repliega, se retira tercamente a su sagrado invencible; vuelve a levantar sus tiendas, ahora ya no en la confianza, ebria de luz, del éxtasis del mediodia, sino en la intimidad crepuscular del rincón inexcusable de cada hombre». (Cit. en Jorge Guillén, edición de Biruté Ciplijauskaité, ed. Taurus, Madrid, 1975, p. 228). 
se afirma en su declaración de no ceder», en un «voluntarioso acto de fe y de resistencia ante lo negativo». ${ }^{26}$

Si en el primer Cántico se respiraba un cierto aire primaveral y en el de 1936 había una fuerza como de mediodía estival, en los Cántico de posguerra parece percibirse ya ciertos tonos otonales a la vez que un dar paso a los agobios y rigores de una Historia que inundará pronto los poemas de Clamor. De manera prácticamente unánime la crítica ha señalado el abandono progresivo por parte de Guillén de la «poesía pura» y su paso a una poesía más «comprometida». ${ }^{27}$ Efectivamente, como en otros de los poemas extensos añadidos al Cántico de 1945, Guillén deja pasar a su libro ese coro de voces negativas, esa parte de sombras que complementan el meritorio esfuerzo de persistencia en la luz de los primeros Cántico, aunque la voluntad del poeta haga finalmente triunfar su voluntarioso optimismo vital. En 1944, Pedro Salinas, íntimo amigo de Guillén, tras felicitarlo por el nacimiento de su nieto, dedicaba sus elogios a ese «otro recién nacido» que era el poema Cara a cara, y señalaba, captando a la perfección la tensión existente en el mismo entre lo público y lo privado: «Ese poema es un maravilloso poema de su tiempo, y de su día, de la fatalidad de lo histórico y la natural aspiración a lo extrahistórico, a lo que no pasa. (...) Porque en él hay más sustancia política que en tanto poemilla de ocasión; la tragedia de la política y el hombre. (...) Es el término más alto del romance, el romance más henchido de tragedia humana, de vida personal y universal. $\gg^{28}$

En Cara a cara cabe ver lo que Oreste Macrí ha llamado «el carácter raciocinante-universalista del tercero y cuarto Cántico», cambio estilístico derivado, según el crítico italiano, de «la crecida voluntad y preocupación por una identificación del yo con el mundo. $\gg^{29}$ En la nueva forma expositiva - sin la densidad inagotable ni el ansia de modificación y renovación iniciales-subsiste una «continuidad estilística», por la semejanza de símbolos puros y de expresiones simbólicas, pero ahora se da «una sintaxis lógica mucho más normalizada, así

26 J. M. Rozas y G. Torres Nebrera, op. cit., pp. 65-66.

27 Valga como ejemplo el trabajo de J. Palley «Jorge Guillén y la poesía de compromiso social» (Hispania, 4, diciembre de 1962): "Guillén, inspirado por Valéry, nos dio su conocida definición: poesía pura es «... todo lo que permanece en el poema después de haber eliminado todo lo que no es poesía». Hay que eliminar la historia, la política, las ideas, las leyendas, la anécdota, la filosofía, etc., en el proceso de purificación. Desde este punto de vista, la poesía de Cántico tiene un alto grado de pureza». (Cit. en Jorge Guillén, op. cit, p. 143).

28 Carta 115, San Juan, 3 de mayo de 1944, en Pedro Salinas / Jorge Guillén. Correspondencia (1923-1951). Edición, introducción y notas de Andrés Soria Olmedo, Tusquets editores, Barcelona, 1992, p. 328.

29 GARCIA BERRIO, A.: La construcción imaginaria en «Cántico» de Jorge Guillén, Limoges, Trames, 1985, p. 505. En nuestro análisis de Cara a cara seguimos de cerca las valiosas sugerencias de esta densa monografía. (En adelante citamos GB). Recuerda asimismo García Berrio cómo el poeta Gil de Biedma señalaba su disconformidad con el sesgo estilístico aportado por «la nueva sintaxis causal, con su «insistencia y prolijidad descriptivas y la articulación excesivamente trabada de sus diversos movimientos». (GB,506). 
y contiguos a los del mundo habitual, que podríamos llamar, incluso, realista» $(\mathrm{GB}, 506)$.

Pasamos a continuación a analizar Cara a cara apartado por apartado ${ }^{30}$ :

I

El poema se abre con la descripción de una tormenta. Guillén - por su «oficio de liberal»_- debió a menudo de hallar reflejada su situación y su estado de ánimo en diversos poemas románticos en los que las fuerzas desatadas de la Naturaleza colaboraban a empeorar el ya decaído espíritu de los liberales desterrados de su patria. ${ }^{31}$

Cuando los alemanes invaden Francia, escribe Guillén a su amigo Pedro Salinas: «iHorrible! Hasta aquí llegan esas nubes de odio que llenan hoy el mundo. No hay quien no tenga agravio que vengar o cuenta que ajustar». ${ }^{32}$ Es difícil no buscar en la temible tormenta física del poema la tormenta simbólica del mal universal -identificada con «el demonio»-, la situación de guerra generalizada que asola Europa a partir de 1939. El resto del poema confirmará pronto lo acertado de tal lectura simbólica.

El observador guilleniano, centro ahora de la ciudad, contempla cómo la tormenta - que acelera el diluirse de las últimas luces del día en un «crepúsculo a deshora»-, somete todo a apretado cerco con su convergencia de sombra y tinieblas. Su inquieta mirada se multiplica ante el espectáculo de un cielo tempestuoso que, surcado por las rayas amarillas de los resplandecientes y cegadores relámpagos descargados por las nubes, semeja la piel de un tigre. Por todos los puntos del horizonte, en las inquietantes afueras, una fosforescencia general predice nuevos relámpagos y le habla de que el tigre sigue rondando amenazante.

El cerco caótico cierra su coso trayendo presagios de noche inminente, símbolo de la muerte en la cosmovisión guilleniana. Los cielos —oscuros, violentos y «múltiples», pues los relámpagos lo segmentan continuamente en mil fragmentos, barajan sus nubes, como cartas de naipes, en azarosos choques eléctricos y presentan un aspecto inquietante: «una sola / Sombra de dominio a plomo». La naturaleza caótica todo lo baraja y desordena, sin dejar nada firme, definitivo. «Nublado»: atrás quedaron los luminosos y diferenciados límites, volúmenes, perfiles. ${ }^{33}$ Un tiempo sin espacio, el de la noche anticipada, desafía al yo del

30 No incluimos el extenso texto del poema, por ser éste fácilmente accesible al lector. Con vistas al análisis topológico que llevaremos a cabo después y que se centrará en los verbos, cuando nos refiramos a ellos los destacaremos en negrita.

31 Nos referimos a poemas como A la muerte de don Joaquín de Pablo (Chapalangarra); En la tormenta de noche. Idilio; La entrada del invierno en Londres, de Espronceda; o El faro de Malta, del Duque de Rivas. No entramos, por no ser éste el lugar adecuado, a detallar las numerosas semejanzas temáticas y expresivas entre dichos poemas y el primer apartado del poema de Guillén.

32 Pedro Salinas/Jorge Guillén: Correspondencia (1923-1951), carta 80, Montreal, 20 de junio de 1940, p. 237. 
poeta. Las nubes sitian - en épica connotación - la ciudad y, como se funden en los campos con las cumbres de las montañas, así ahora se funden con lo más elevado de la urbe: sus «torres y cimborrios». Si los románticos solían pintar al olmo erizado, estirado, y arrancado al fin por el viento tempestuoso, Guillén presenta la imagen ascensional de un chopo que se aguza, se afila, como si se erizase ante el relámpago. Se extingue un trueno a lo lejos en medio de la aliteración, tan romántica, del fonema vibrante múltiple («retumbo», «derrumbe sordo»). Los troncos de los árboles toman el color de lo inexacto: se ahúman. Se enluta el cielo y todo se va diluyendo, sin el perfil exacto que la luz daba a cada cosa, en las sombras que derrama el anticipado crepúsculo, por lo que se hace obligado el uso temprano de la luz eléctrica. ${ }^{34}$ Luces de la ciudad en torno a las que las gentes se congregan, ya protegidas de la tempestad.

El yo siente algo inefable amenazante: una anónima hostilidad zumba fuera. El crepúsculo, por la falta de luz, conlleva tedio, melancolía y sentimientos difíciles de expresar con palabras: como un naufragar en un charco de «lodo» ${ }^{35}$, en una tarde ensuciada, triste. Hay un no sé qué de animal en esa tempestad de fuera que no deja de escarbar, de remover con sus pezuñas, y que va abriendo hoyos de los que emergen desparramándose, -invadiéndolo todo, asfixiando todo de modo sofocante- una «fosca / Pululación del bochorno», un «hervidero». ${ }^{36}$ Frente a los dioses de la claridad, el optimismo y el orden, continuamente invocados por Guillén, la tormenta exterior sólo trae oscuridad y vagas amenazas.

Nos devuelven al inicio del poema los nuevos relámpagos en que se rasgan

3. El duque de Rivas inicia así El faro de Malta: «Envuelve al mundo extenso triste noche,/ ronco huracán y borrascosas nubes / confunden, y tinieblas impalpables, /el cielo, el mar, la tierra, / y tú invisible te alzas, en tu frente / Ostentando de fuego una corona / cual rey del caos, que refleja y arde / con luz de paz y vida. / En vano el ronco mar alza sus montes / y revienta a tus pies, do, rebramante, / creciendo en blanca espuma, esconde y borra / el abrigo del puerto. / Tú, con lengua de fuego, «Aquí está», dices, / sin voz hablando al tímido piloto, / que como a numen bienhechor te adora.» Como veremos, también Guillén se alzará, cual faro de luz, ante la tiniebla que confunde y borra los límites, es decir, que todo lo baraja.

${ }^{34}$ La tarde funciona en Guillén como «apercibimiento disolutivo y degradación óptica de consistencias, propagadora ya de incertidumbres enigmáticas», y hace entrar en crisis «la óptica exploratoria del ser» $(\mathrm{GB}, 217)$. En los textos de atardecer y puesta de sol culmina la «difuminación y desdibujado de las evidencias existenciales exaltadas por la luz matinal, en contacto con el tiempo y el declive vespertino de la intensidad luminosa» (GB, 219). La tarde es «símbolo de entregado abatimiento, de sumisión derrotada, arreciada de pánicos» $(\mathrm{GB}, 220)$.

35 En el poema Paso a la aurora la lluvia y el fango son símbolos del espacio caótico nocturno: «impureza, oscuridad chapoteada». También en $A$ vista de hombre confluyen, como símbolos amedrentadores, la lluvia y el chapoteo del barro: « "Acecha un fondo hostil. / (...) / Vaivenes de negruras abalanzan / Su incógnita a la tierra». García Berrio destaca cómo el poeta, por medio de estas «formas de poderosa alusividad de lo indefinible», «casi roza el milagro de conformar el caos, de diseñar corrientes de consistencia intuitiva en el alojamiento informal de la nada» (GB, 485-486).

36 La «animación caótica» suele ser sugerida por Guillén en otros poemas de Cántico a través de palabras como «pululación» o «hervon» (GB, 505). Véase: Férvido: i...cuánto hervor de crepúsculo!», Noche planetaria, donde el insomne desde su lecho «Siente la oscuridad / Como una polvorienta / Pululación en torno» o Presagio: «pululación en negro de lo hondo». 
Nos devuelven al inicio del poema los nuevos relámpagos en que se rasgan los cielos. Los agresivos amarillos nocturnos y los cárdenos son colores que Guillén moviliza para simbolizar el persistente cerco amenazante. Pero cuando parece que el apartado I del poema va a cerrarse de la misma manera en que se abrió, la posible circularidad se rompe en los dos últimos versos. El misterioso caos rodea al yo, que siente la inmediata tentación — vivida de antemano como infructuosa- de rebelarse contra el cerco en busca de la liberación. ${ }^{37}$ Sobreponiéndose al miedo, la voz del solitario héroe guilleniano, desde el centro de la experiencia, asegura desafiante, a la vez que expresivo y coloquial: «Pues... aquí estoy». Ceder, acobardarse, sería la reacción esperable de cualquiera. Sin embargo, él se alza en rebeldía --voluntarioso ángel-luminoso-frente al demonio-caos.

\section{II}

No nos sería nada difícil acumular aquí testimonios bien elocuentes de la actitud de Guillén frente a las monstruosidades de los bandos enfrentados en la guerra civil española o en la europea, de su independencia y dignidad, hombría aristocrática, orgullo superior, tenacidad altiva y sagaz «egocentrismo», en una resistencia de profundo sentido ético (GB, 27-32). Destaca García Berrio la «inequívoca voluntad de descartarse», nunca ocultada por el poeta $(\mathrm{GB}, 30)$, quien «desdeña toda forma de dispersión, como la civil, a la que hace frente, resueltamente en Cara a cara» (GB, 32). Tras desafiar a la tempestad de la Naturaleza en el apartado I, el héroe guilleniano planta cara a la amenaza caótica de la Historia, a una generalizada situación de injusticia y desorden moral en el mundo. ${ }^{38}$

Comienza ahora un largo soliloquio en que el poeta va a constatar ante los demás - actitud explicitada en ese ved - su inevitable implicación en los errores de los hombres, errores que se asoma a su rostro. A sus ojos, los bandos enfrentados —el «ogro» y las «víctimas»— son equivalentes, cómplices a fin de cuentas: «iMe dan lástima los oprimidos, y también los opresores. ¡Qué futuro

37 Sobre la ejemplaridad de la valiente actitud del héroe guilleniano, véase el análisis que el profesor García Berrio hace del poema de Guillén Noche del caballero, centrado en la figura de don Quijote y en el que también aparece el demonio rasgando la tiniebla (GB, 389-392).

38 Desde Wellesley, el 28 de febrero de 1942 escribe Guillén a Salinas y, comentando el suicidio de Stefan Zweig, ocurrido el 23 de febrero de ese año, señala: «Pero lo que despierta en mí más piedad - al mismo tiempo que admiración-es que una vida humana se consuma íntegramente dentro de la Historia. Sublime, sí. ¿Y no había más? Pienso en lo que don Miguel llamaba la intrahistoria: esa cotidianeidad sin fecha —el sol, la manzana, el hijo, la mujer, el trabajo de cada día, esta carta al amigo, esta ventana: exactamente, lo que que no es Historia, Actualidad y podría ser Poesía, Poesía no-histórica. Esto no es la doctrina de Cántico: así es como viven y van saliendo adelante las miles de gentes, no deshechas del todo - iaun!- por la Historia miserable que tan pequeño margen disponible deja en estos miserables días. (...) En fin, dejemos la Historia con su miserable mayúscula.» (Correspondencia (1923-1951), carta 93, pp. 276-277). 
se preparan!», dirá Guillén al comentar la inmediata posguerra española. ${ }^{39}$ Por eso se nos presenta a continuación la imagen de un país «Polvoriento, populoso».40

El hombre, sin máscaras, muestra sus morros húmedos de «animal / Cínicamente velloso». Las políticas se contagian de animalidad: imposible unirse a bando alguno quien quiera ser hombre. Todos conspiran, se confabulan contra la paz y la dignidad humanas. Los dos bandos, barajados en la tormenta de la Historia, se han tornado un único bando indiferenciado, envuelto en el común rojo de la iracundia, la vergüenza y la sangre de sus crímenes de horda ${ }^{41}$

Se nos sugiere a continuación un mundo de cárceles, de presos: fuera, el aire libre y la luz del alba contra el blanco purísimo de la cal; dentro, el yo del preso desdibujado en la sombra carcelaria, frustración de la luz y del aire, que constituyen el espacio del hombre. ${ }^{42}$ La boca del preso - itan diferente de los morros húmedos del animal violento y satisfecho que ha citado poco antes! está siempre seca, de pasar hambre y sed y de vivir en continuo amargo soliloquio. Y resistiendo a la tentación del reposo, ante la nostalgia de paradisíacos jardines otoñales —el jardín es símbolo de fresco refugio en el universo poético guilleniano, como antes lo fue en el de Gabriel Miró - se alza de nuevo la voz del poeta: «No cedo, no me abandono». Aun admitiendo su «inaptitud» para luchar contra el mal y el dolor, su dignidad —como al final del apartado I — le obliga a desafiarlos en valiente actitud de protesta.

\section{III}

Comienza en este apartado la serie de condicionales que continuará en IV y con las que Guillén anticipa futuras situaciones comprometidas: si los dioses de unos y otros lo condujeran al martirio («foso»); si las guerras desmenuzasen los países y rompieran las fronteras ( $«$ y se me clavan / Los añicos entre escombros») y el yo hubiera de sacrificar su individualidad ante el remolino

39 Correspondencia (1923-1951), carta 72, Montreal, 1 de marzo de 1940, p. 221.

40 Bien pudo haber tenido en cuenta Guillén al redactar el comienzo del apartado II estos versos del poema de Espronceda «iGuerra!»: «El pueblo ved que la orgullosa frente / Levanta ya del polvo en que yacía, / arrogante en valor, omnipotente, / terror de las tiranías». Utilizando idéntica invitación que Espronceda —Ved»-, Guillén opone a la imagen ascensional, orgullosa de un pueblo alzado para su liberación, la idea de vergonzosa resignación ("pesadumbre», "pesan») del país después de un monstruoso conflicto civil.

${ }^{41}$ «Claro queda el sentido de su orientación en la contienda presente entre monstruos y paladines, claro e inalterable; pero, al más alto precio del enojo de sus paladines, no deja de señalarles su rebajamiento a la «iracundia común» de la historia y el accidente existencial» (GB, 30).

42 ¡Cómo no recordar aquí la circunstancia humana y la poesía última de un Miguel Hernández, con su épica lucha entre la luz y la sombra! Desde Wellesley, el 26 de noviembre de 1942, escribe Guillén a Salinas: «Otra noticia, y ésta, en serio: he leído en los Cuadernos Americanos que el pobre Miguel Hemández murió el 28 de marzo en la cárcel, tuberculoso. ¡Otra víctima de la guerra civil! Me ha producido verdadera pena esa noticia: Miguel Hernández era, hasța ahora, el mejor de su generación.»(Correspondencia (1923-1951), carta 100, p. 293) Y el 12 de diciembre de ese mismo año, califica de «muerte idiota» la de Miguel en plena posguerra (Ibid, carta 102, p.297). 
la unidad perdida. La luz de los astros será la inevitable ayuda ante tal confusión. Con la seguridad que halla en la luz - «el ámbito propio de la esfera luminosa, dominio específico para el ejercicio de la humanidad» (GB, 346-7)—el héroe sabrá arreglárselas, componerse «La paz de un islote propio», restándose a la disgregación general. Centro del equilibrio de nuevo, salvaguardará su soberanía individual. Por eso ahora vuelve a darse una respuesta consoladora: aunque todo se derrumbe, siempre se salvará del caos general un tesoro: la libertad. ${ }^{43} \mathrm{El}$ ejemplar héroe guilleniano, nada insolidario, parece ofrecer esta salida: ante el caos, todos deben salvaguardar su luz, su libertad, que nadie podrá arrebatarles. Moralmente es una imperiosa necesidad la de salvar la luz en medio de las tinieblas de la Historia.

\section{IV}

Continúa la serie de condicionales que se abría en III con sus presagios de malas horas: si, por un presente doloroso, llegara la desesperación al corazón del poeta y el dolor socavara, perforara en el mismo un pozo que lo hundiera hacia la Nada ignorada («mi gozo en un pozo» se dice coloquialmente)...; si los años lo tornasen «Crepúsculo de rastrojo»" si las alegrías, abandonándolo, dando de lado a su «decoro», revolviendo su normal compostura, se decidieran a no colaborar en la dignidad y el optimismo que aparentó siempre; si los grises — símbolo en Guillén del umbral de la Nada- nada cálidos, inconsistentes, de los cerros, último límite antes de la tiniebla nocturna, «Con sus cenizas de lunas / En horizontes de polvo» le llevaran presagios de muerte, todo ello no vencerá ni apagará el rescoldo «De mi afán por las esencias»: de nuevo la luz dando seguridad al poeta. ${ }^{45} \mathrm{Y}$ frente a imágenes negativas acumuladas —como «pozo» o «Crepúsculo de rastrojo», connotadoras de hundimiento y acabamiento-, frente a la angustiosa pregunta que el héroe se pueda hacer al hallarse ante los umbrales de la Nada, otra vez la contestación autoconsoladora, tenaz, optimista, desafiante y voluntariosa:

43 Cara a cara nos hace pensar a menudo en la Canción del pirata de Espronceda, con la que comparte el tono de desafío y el deseo de marcar con decisión el espacio propio frente al de los demás.

44 Imagen hiperbólica muy expresiva que nos recuerda los versos 16-18 del Miguel Hernández de la Elegía a Ramón Sijé: «Ando sobre rastrojos de difuntos, / y sin calor de nadie y sin consuelo / voy de mi corazón a mis asuntos». (El subrayado es nuestro).

$45 \mathrm{La} \mathrm{Luz}$ «ofrece en su relieve eurítmico el resalte de los objetos y los paisajes de su entorno, puebla de variedad organizada el ámbito del hombre; éste encuentra en el espacio luminoso causas suficientes para el ensimismamiento apasionado y jubiloso, para la animación jocunda. La destitución de la luz reduce el espacio de la reflexión, lo adensa en la monotonía caótica (...) La vida, triunfo de la luz, es bien supremo, la muerte, espacio caótico de la sombra, es la más absurda forma de castigo. Yo sé bien cómo el optimismo de Guillén vivía asido a la delicia de la luz, con una fe ejemplar de perpetua acción de gracias al autor de tanta creación maravillosa; y sé cómo y cuántos se rebelaba -con ejemplar compostura - contra el sinsentido de la oscuridad, prueba difícil para una naturaleza engendrada en la luz a la conciencia de centro autónomo en libertad» (GB, 392). 
Heme ante la realidad cara a cara. No me escondo,

Sigo en mis trece. Ni cedo

Ni cederé, siempre atónito.

(Cántico, p. 520)

El héroe guilleniano se quiere permanentemente estupefacto, maravillado, pasmado, suspenso, ante la realidad del mundo. ${ }^{46}$

$\mathrm{V}$

Brilla en este apartado — tan cercano al poema de Guillén El concierto- la temática de la música. Por un lado, aparece «la música callada» de fray Luis; por otro, la que según los románticos constituía el arte más idóneo para expresar el alma, la voz de la naturaleza, lo inefable en suma. Como si tras afirmar el poeta su firme decisión de no ceder, una voz le dijera «Cederás, ya lo verás, la realidad te obligará a ello", éste asegura no ignorar la futura vuelta de las horas de los pesimismos, las desgraciadas horas de la Historia - ya conocidas, por las guerras española y mundial-, que asomarán cual negro toro amenazante, que convergerán hacia él «En tropeles inarmónicos» amenazando su silencioso descanso, su paz personal. Y entonces expresa su firme creencia en la «música / Tácita» a la que responde, en ese armonioso acorde que coexiste con el «embrollo» de la Historia y que, aunque a veces parezca desaparecer como un Guadiana, permanece ante él. La amenaza está en el "desbarajuste» de la Historia - de nuevo la amenaza del barajar que ya aparecía en la tormenta del apartado I-, que parece perdurar. A base de didácticas preguntas y respuestas y antítesis léxicas, el yo defiende su derecho al silencio, a un refugio frente al caótico chirriar de la Historia. Su fe le dice que bajo el aparente caos hay un orden: «Algo se calla más hondo». Como tantos poetas videntes del Romanticismo, sabe deslindar, reconocer las «esencias» —recónditas armonias- entre los «accidentes» —ruidos de la Historia-. Él es el director de la orquesta de sus silencios.

$Y$ en esta defensa de sus derechos será un importante aliado el cristal de su ventana, pobre refugio, pero refugio al fin y al cabo..$^{47}$ Por si alguien quisiera

46 Queremos recordar aquí un pasaje de «Don Jesús y el judío errante», de El humo dormido de Gabriel Miró, citado por el mismo Guillén en su ensayo sobre el alicantino («Gabriel Miró. Lenguaje suficiente», en Lenguaje y poesía, Alianza, Madrid, 1969, p. 179), en el que afirma don Jesús: «Lo que pido es el hombre sin Angel de la Guarda a la derecha, ni Demonio a la izquierda. El hombre cara a cara de sí mismo; que le duela el pecado por haberse ofendido a sí mismo; que le resuene toda la naturaleza en su intimidad; atónito y complejo; más hombre que persona.» (El subrayado es nuestro). Creemos que el pasaje sintoniza bien con estos versos de Guillén y, por ello, aun descontextualizadamente, lo hemos recogido aquí. La postura deseada por don Jesús es ejercida continuamente en Cántico. Baste un ejemplo de $A$ vista de hombre, $\mathrm{II}$ : «Atónito de nuevo, más admiro / Cómo todo responde a quien pregunta». 
combatir su silencioso apartamiento, su acogerse a la propia subjetividad, señalándole la Historia y sus sangrantes problemas, se apresura a afirmar que nunca el sol de todos, ante el que sueña, lo hallará evadido en torres de marfil ni escondido ante la realidad.

VI

Al presentarnos Guillén al mal que mientras, allá fuera, en la Historia, tras su ventana - gesticulante, colérico y de visaje torvo-, viene actuando «desordenando los modos», nos hace recordar un verso de Meléndez Valdés: «Si el Dios del mal el mundo desordena»... Paradójicamente, el desorden coadyuva a la labor positiva del héroe guilleniano. Tras reiterarse distintas imágenes del cerco a que el mal lo somete -la «angustia», el «oleaje» que lo circunda y rompe contra sus defensas, la «Continua tensión»-, el yo afirma que tal cerco colabora a situarlo en el centro de la verdad, desde donde puede acosar a su vez, contratacar con «ímpetu». Reconoce claramente necesitar, ambicionar la contradicción y el «alboroto», fatales complementos dialécticos, pues su estar en tensión, su afrontar la realidad más real, favorece cada día su búsqueda decidida de las armas que le van a permitir avanzar victoriosamente. En tal desigual y épico forcejeo con los «accidentes», el yo obtiene seguridad de su pacto estratégico con «la esencia» (verdad, bien y belleza o «hermosura»). Define Guillén tal pacto como «Virtud radiante, negocio / De afirmación», negación de cualquier ocio evasivo o cobarde. El yo, el microcosmos humano, «lo poco», adquiere plena conciencia de la potencia de su ser gracias a la luz, que también ilumina para él las bellezas del macrocosmos, «lo mucho». Recargadas las baterías en la luz, el yo se arroja, ávido, al mundo, que lo convoca e invita. Venciendo cualquier temor, el ser, que sabe que le basta con ser, se yergue desafiante: sus hombros resisten y sostienen. Y si al comienzo mismo de Cántico, en el hermoso poema Más allá, leíamos:

(El alma vuelve al cuerpo, Se dirige a los ojos

47 Tras caracterizar a Guillén como «Hombre de casa, de gabinete, biblioteca (...) y cuarto familiar» y destacar como típico de Cántico el «interior doméstico», señala García Berrio como primero de los mitos poéticos de Cántico «la habitación, el espacio inmediato relativamente seguro, el ámbito de las primeras y de las últimas consistencias» $(\mathrm{GB}, 353)$. Y continúa: «La ventana acristalada es desde luego el símbolo obvio de comunicación y apertura que han exaltado los críticos de Guillén; pero hay que señalar también entre sus funciones otra fundamental de limitación y de filtrado. El cristal establece con frecuencia su límite inexorable al murmullo desbordante de la ciudad hostil, del semejante peligroso en multitud (...) la ventana acristalada aporta además en su condición de espacio perforado, limitado, orlado de pared impenetrable, un orden de visión extremadamente definido; vía simultánea de admisión y de exclusión, de selecciớn de espectáculos y abdicación a puros rumores» (GB, 353-354). 
Y choca.) - ¡Luz! Me invade

Todo mi ser. ;Asombro!

(Cántico, p. 17)

en los versos finales de Cara cara - y curiosamente con las mismas rimas- se redondea el Cántico de 1945 en un idéntico optimismo, acaso más voluntarioso:

Mientras se agrandan los ojos

Admirando cómo el mundo

Se tiende fresco al asombro.

(Cántico, p. 524) $)^{48}$

\section{(II) ENFOQUE SEMÁNTICO-TOPOLÓGICO}

Partimos de la siguiente hipótesis de trabajo: si la teoría sobre los Universales Lingüísticos - apoyada en los formalismos de la TC de Thom-es «verdadera», entonces ha de poder falsarse en el dominio lingüístico. Bien es cierto que este concepto de falsación no tiene aquí el sentido popperiano - la teoría puede ser refutada por medio de contrastes y pruebas empíricas-, sino otro mucho más lato; en palabras de Petitot: «Manifiesta una propiedad reseñable que puede ser sometida al test de la experiencia y que es, por tanto, falsable». Y continúa en nota: «Lo que nos hace salir de una semántica descriptiva y acceder a una semántica formal efectiva donde la formalización no queda sin consecuencias». ${ }^{49}$

Pues bien, nosotros sugerimos que una manera, entre otras, de comprobar la fertilidad de la TC en Linguística es la de averiguar si, tal como asegura la teoría, los verbos -que Thom considera como trayectorias en el despliegue universal de una catástrofe espacial con un punto de parada cuando esta trayectoria corta transversalmente el conjunto de bifurcación ${ }^{50}$ - se ordenan por su natural de la manera en que señala la jerarquía entre las diversas figuras semánticas desde el pliegue hasta la umbílica parabólica. ${ }^{51}$ Trataremos de corroborar esta hipótesis en el poema que estamos analizando, del que no puede decirse que esté

48 García Berrio ha destacado cómo, aunque existe «una frontera convergente en temas, fómulas imaginarias y biografía entre Cántico y Clamor», «la disciplinada tenacidad de Guillén se esforzó, hasta el riesgo poético mismo, en mantener el júbilo sobre la angustia en el tono global de las composiciones de una obra que Guillén quiso siempre, durante más de treinta años, que significara la expresión en triunfo de un optimismo espacial impuesto sobre exclusiones disciplinadamente mantenidas. Cántico opone así júbilo a claroscuro, no a abierta zozobra existencial; sin espacio aún definitivo para el fomento abierto, para la caída en fuga en el abismo noctumo» $(\mathrm{GB}, 497)$.

49 PETITOT, J.: «Topologie du carré sémiotique», Etudes Littéraires, Québec, Univ. de Laval, 1977, p. 63.

so THOM, R.: MMM, pp. 236-237. 
hipótesis en el poema que estamos analizando, del que no puede decirse que esté construido ad hoc para ejemplificar la teoria, y observaremos qué ocurre. Indudablemente, sería absurdo suponer que cualquier texto y en cualquier ocasión admitirá el análisis de la Semántica Topológica. a) En primer lugar, porque la TC sólo tiene capacidad, por ahora, para expresar las figuras más simples, lo que se llama la Teoría Elemental de la TC. b) En segundo lugar, porque la complejidad del argumento puede dotar a los textos de un carácter muy rebuscado y artificioso. Por lo tanto, tenemos que descubrir estas jerarquías semánticas en textos en los que los verbos intervengan de manera muy simple, sin farragosas complejidades (inabarcables todavía al análisis que pretendemos).

La elección del poema de Guillén tiene un interés especial por su acusado afán de estabilización de los verbos hasta alcanzar el Ser, ${ }^{52}$ que es un verbo cerovalente en la terminología de Tesnière y de despliegue cero en la topológica. Así, en el siguiente poema podemos comprobar esta característica guilleniana de tratar de permanecer en el ser (al lado escribimos la fórmula de la singularidad dominante):

$\begin{array}{ll}\text { ESTAR ...-- } \mathrm{x}^{2}-\ldots & \begin{array}{l}\text { «Más persuasión? Yo no la necesito. } \\ \text { Poco a poco los párpados, la frente } \\ \text { Tratan de seducirme, ya indolente, } \\ \text { Cuando soy yo quien se propone el hito }\end{array} \\ & \begin{array}{l}\text { Feliz. Mi propia dejadez imito } \\ \text { Para que a fuerza de olvidarme asiente } \\ \text { Mi vivir en la nada más clemente. }\end{array} \\ \text { VIVIR ...-- } \mathrm{x}^{3}-\ldots . & \text { iDulce anonadamiento del bendito! } \\ & \text { Ni esbozo de ultratumba ni descenso } \\ & \text { Con fantasmas a cuevas infernales }\end{array}$

s1 Según la jerarquización siguiente:

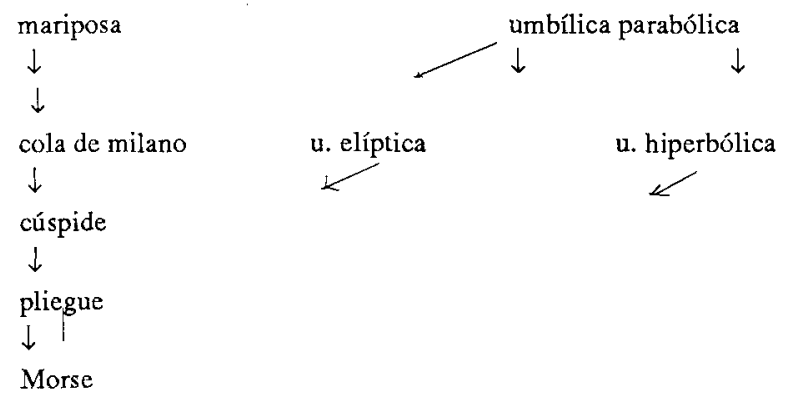
p. 190.

POSTON, T. y STEWART, I.: Catastrophe Theory and its Applications, ed. Pitman, London, 
Donde imperen oráculos de ayer

S6́lo sumirse en el reposo denso De una noche sin bienes ya ni males, SER $\ldots--\mathrm{x}^{2}--\ldots$ $\mathrm{Y}$ arraigarse en el ser y ser. ¡Ser, Ser! (Cántico, p. 284).

La tendencia por alcanzar el ser explica, seguramente, la dificultad de detectar verbos complejos, como umbílicas en Cántico. En nuestro lenguaje, esto se debería a ese continuo «volverse hacia el ser», hacia una estabilidad máxima, que hemos señalado como del tipo $\mathrm{x}^{2}$. Aunque en algunos poemas se vea obligado a utilizar verbos más complejos para expresar, sobre todo, su lucha contra un mundo agresivo que le coloca en encrucijadas de muy difícil resolución y que, como hemos indicado - apoyados en Berrio-, es un cambio de actitud que se produce en Guillén más por su intento de apertura al Mundo, que de exclusiva identificación con el Ser.

Cara a cara de Cántico responde de manera ideal a nuestro análisis, pues consideramos que todo el poema queda dominado por un verbo cuya semántica es una singularidad umbílic a parabólica: dos variables internas (i. e., dos modos de conducta, cuya representación es compleja, una línea deslizándose por un plano) y cuatro variables de control. Lo interesante de esta figura $o$ arquetipo semántico es que sus secciones contienen al resto de singularidades. El verbo dominante no sólo quedaría estabilizado al desplegarse a través de sus actantes, sino que se vería enriquecido ante la mirada del lector al ser matizado mediante múltiples verbos que supondrán proyecciones suyas, en otras variedades topológicas $n$-dimensionales.

Los verbos que presiden todo el poema son: barajar y ser, verbos opuestos, antitéticos. Ante el temor de ser barajado, el sujeto busca el medio de estabilización máxima, el ser. Pues lo que subyace en el poema es la lucha, verdaderamente épica, entre el mundo y el poeta.

\section{I'}

El primer apartado del poema se halla constituido por tres saliencias, que provocan diversas pregnancias. Una saliencia es, en la ontología de Thom, toda forma experimentada que se separa netamente del fondo continuo del cual aquélla destaca. Algunas de entre estas saliencias provocan una reacción de gran amplitud en el sujeto: liberación de hormonas, excitación emotiva, atracción

52 Este tipo de poesía esencialista ha impregnado a muchos poetas, generalmente jóvenes, que tratan de alcanzar esa plenitud expresiva depurando al máximo el sistema verbal. Veamos un ejemplo: «Es el tiempo / de empezar el instante / que se acaba ahora / y no nace / entre trampolines vacíos / las huellas resbalan siempre / a cada paso / es el tiempo/que se acaba / en un sueño/despacio / hasta que el sueño en que muero / pensándome de agua / me esperaré en las raíces / donde despertaré de morir / hasta morir en sueños / llegaré / al instante...». BARCELO, Adriana: La luz que huye, ed. Aguaclara, Alicante, 1991, p. 40. 
o repulsión, etc. A estas formas Thom las llama pregnantes (la psicología de la Gestalt hablaba de Prägnanz), y pregnancia a ese carácter específico..$^{53}$

1. El poema se abre con unos versos en los que el poeta se dispone a llamar la atención precisamente dibujando una primera saliencia, un deslumbra que actúa de manera local: cierra su coso. El concepto de localidad es fundamental en la teoría de Thom, teoría que, como hemos dicho, es topológica, y una de las maneras de definir la topología es, precisamente: ciencia de los bordes, de los contornos. $^{54}$

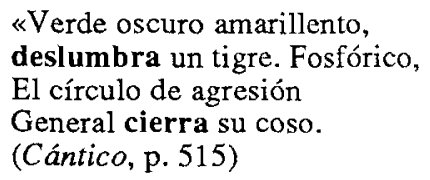

Una vez captada la atención, el verbo que dominará topológicamente un conjunto de quince versos es barajar, cuya semántica identificamos con una umbílica parabólica. Según nuestra hipótesis, este verbo, como centro organizador que es, debe dominar todos los demás verbos, que han de quedar subordinados a él según el esquema de la nota 49. Que el verbo abarque todo el mundo en el que se lleva a cabo la descripción del poema es intención explícita del propio Guillén:

Aun los cielos se barajan

-Múltiples, bárbaros, lóbregos-

Para formar una sola

Sombra de dominio a plomo.

(Cántico, p. 515)

Como las proyecciones posibles son teóricamente infinitas, el poeta «elige» aquellas que mejor cuadran a su propósito. Aquí, el formalismo no puede dar cuenta de los verbos de una manera deductiva, puesto que, según se ha indicado, las reglas algebraicas o lógicas no son capaces de dar cuenta de una semántica tri-dimensional. Lo intentará, pues, a través de proyecciones, y para ello se necesitan esquemas analógicos de interpretación. En este caso el verbo barajarcuya trayectoria queda definida mediante cuatro actantes — una parte de los

53 Escribe Thom: «El fenómeno lingüístico puro es en efecto la catexia (objetiva) de una forma saliente por una pregnancia. Como la predicatividad pone en tela de juicio un género cuyos eide son fijos, la aserción del predicado basta para caracterizarlo (como predicado). Pero los actuantes relacionados por la valencia con el predicado - los nombres - no están en principio localizados. De ahí la necesidad de indicar (mediante deícticos o métodos semejantes) esta localización que al principio está indeterminada y necesita auxiliares apropiados de naturaleza demostrativa para estar fijada». Semiofísica, op. cit. p. 224.

54 THOM,R.: MMM., pp. 120, 136-137. 
cielos (en forma de nubes), otra parte de los cielos, la carga eléctrica, y los rayos y truenos a que da lugar- ${ }^{55}$ está dibujado mediante tres saliencias ${ }^{56}$ distintas:

La primera saliencia, ya citada, inicia la semántica de cuatro verbos (las pregnancias a que da lugar), los cuales, repetimos, son proyecciones del verbo barajar: sitiar, aguzar, ahumarse, derramar.

๙) «Las nubes sitian / A las torres y cimborrios / De la ciudad ...» Sitiar es un verbo del tipo cúspide.

$\beta)$ «Se aguza un chopo / Bajo un retumbo...». Aguzar sería una proyección cúspide regida por el actante «trueno», que inmediatamente después se extingue (pliegue).

$\gamma)$ «En el aire cruelmente / Blando se ahúman los troncos». Ahumar sería una cúspide regida por los actantes «blanco-chopo» / «negro».

ઈ) «Derrama en el día golfos / De una oscuridad que pide / Luz urgente de socorro.» Derramar oscuridad sería una proyección cúspide regida por los actantes «rayo» / «relámpago».

Como hemos visto en el análisis tradicional, el verbo barajar supone la amenaza máxima a la individualidad del sujeto, amenaza reiterada a lo largo del poema por otros verbos, que son sus proyecciones.

En el caso de sitiar se lleva a cabo como una parte transversal de barajar. La ciudad se torna campestre por diluirse las fronteras entre campo y ciudad en el nublado general.

Aguzar es consecuencia del barajarse de luces, de las apariciones súbitas e inesperadas a causa de la iluminación de los relámpagos.

Ahumarse se lleva a cabo como un barajarse de colores que hace perder al árbol su coloración.

Desparramarse se lleva a cabo como un barajar todo en una inundación de oscuridad.

2. En la segunda saliencia las luces del hogareño refugio brindan seguridad ante la tormenta. Encenderse también queda localizado al recogerse en los conos de luz:

«Se encienden lámparas íntimas

Que recogen en sus conos

De resplandor esos ámbitos

5s La razón de esta estabilidad hay que encontrarla en la Mecánica y la Física. THOM, R.: $M M M$, p. 248.

56 Según nuestro análisis, la primera de las saliencias debería hallarse impresa separada hacia la derecha, como lo están la segunda y la tercera.

En la disposición tipográfica habitual del poema (usamos la edición de Cántico de Seix Barral, 1974) lo que se destaca hacia la derecha es el atractor (vs. 5-8) y no la pregnancia (vs. 1-4). Sería interesante comprobar lo acertado de nuestra suposición teniendo delante el manuscrito del poeta. Se non é vero, é ben trovato. 
Se trata de una saliencia que ilumina el interior de las casas, de radio menor al de la primera saliencia, pero que provoca pregnancias del mismo tipo que las del verbo deslumbrar. Dice el poeta que «hay una desolación», producto de la amenaza de lo múltiple, lo impersonal, lo vago y lo anónimo; barajar es eliminar perfiles y volúmenes, es combinarlo todo aniquilando sus precisos contornos. Ahora se inician otras pregnancias que explican la desolación mediante verbos como los siguientes: zumbar (mariposa) y escarbar (umbílica hiperbólica); emerger desparramándose (mariposa) y asfixiar (pliegue).

3. Al concluir las proyecciones del «hay una desolación», vuelve a dibujarse una saliencia, la tercera, que nos conduce de nuevo a la amenazante naturaleza exterior:

\author{
En relámpagos se rasgan \\ los cielos hasta esos fondos \\ Tan vacíos que iluminan \\ Los cárdenos dolorosos. \\ (Cántico, p. 516)
}

El verbo rodear (cúspide) es la pregnancia provocada por dicha saliencia: «El agresor general / va rodeándolo todo». Y cuando parece que el poeta va a rendirse a su asedio, siendo capturado, un grito rompe el equilibrio, para producir nuevas morfologías: «Pues... aquí estoy. Yo no cedo. / Nada cederé al demonio».

Pero ante tal poder demoníaco - la nada, la tempestad aniquiladora que baraja y mezcla todo en el caos general (pululación, hervor...) - el poeta, en lugar de tender, como es usual en Cántico, a la estabilidad metafísica, dado que $\mathrm{e}^{x}$ reposo es imposible, se exige a sí mismo una resistencia activa, que lo obliga a continuar el poema.

II

Así procederá, en un largo soliloquio, a reflexionar sobre su posible respuesta ante el dolor y el mal del mundo, que lo inquietan y acosan llenándolo de vergüenza. Incluso insinúa una saliencia, no de la naturaleza, sino humana (Guillén habla de «errores» y errare humanum est), a la que sigue enseguida un «chorro» de cúspides, que entendemos como explicativas, pues el poeta medita sobre las numerosas identidades que presenta el mundo - ahora no a escala natural, sino moral-humana- y en las que se produce la aniquilación de las formas concretas. Por eso el poeta utiliza cúspides, sugiriendo que en estas figuras (microcósmicas) tienen lugar las identificaciones de actantes, que son absorbidos por otros actantes y quedan neutralizados en ellos; hay un temor a quedar 
anulado en el barajar general.

V. gr.: «Equivalencia final / De los unos y los otros: / Esos cómplices enlaces / De las víctimas y el ogro, »; «Que envuelve en el mismo rojo / De una iracundia común / Al paladín con el monstruo»; «Extenuación de la cal / Sobre los muros monótonos, »; «Y en la boca - siempre seca- / Tan amargo el soliloquio»; «Ese instante de fatiga / Que sueña con el reposo».

Recordamos que una cúspide describe típicamente las morfologías de apresamiento. Al iniciarse el proceso hay dos actantes: los unos / los otros, en este caso. Entre ellos se establecen relaciones lingüísticas, de amistad, de odio, etc. Pero al terminar el proceso sólo queda uno, el sujeto, que, si bien triunfa sobre la catástrofe, al identificarse con el otro actante, se ensimisma, se enajena, convirtiéndose el diálogo en «soliloquio», el esfuerzo en un sueño de quietud, etc.

$\mathrm{Y}$ ante todas estas cúspides, que avisan al poeta de su posible futura aniquilación, éste se reafirma en su voluntad de resistencia y de defensa activa de su individualidad:

¡Imperen mal y dolor!

En mi semblante un sonrojo

De inaptitud se colore.

No cedo, no me abandono.

(Cántico, p. 518)

III'

Por lo que tratará de hallar, ante los ineludibles y problemáticos presente y futuro (el dolor, la guerra, la vejez y otras proyecciones semejantes del verbo barajar), el mediador que le permita luchar por la paz. Y lo encuentra en los ASTROS (la luz), pregnancia que le mantiene aislado, singularizado, enfrentado en el campo semántico, como un atractor más, frente a todos los que están sometidos al verbo barajar:

guerra $\longrightarrow$ ASTROS $\longrightarrow$ paz.

Todos los verbos que ahora intervienen son singularidades de menor potencia germinal que el verbo barajar, que los domina, tal como venimos defendiendo: conducirse (pliegue), desmenuzarse (mariposa), clavarse (umbílica elíptica), sufrir (umbílica elíptica), llega: la noche (pliegue), haber (cúspide), no fallar (cola de milano), componerse (cúspide), arrebatar (cúspide), anularse (cúspide).

IV'

El verbo barajar se expresa ahora con sus posibles resultados: doler (cúspide), 
hundirse (umbílica hiperbólica), tornarse (cúspide), huir (cúspide), enfriarse (cúspide). Si el verbo revolver -como verbo sinónimo de barajar que es-se impusiera con todas sus consecuencias, entonces el ser sería absorbido y hecho desaparecer. Pero esto no ha ocurrido ni ocurrirá. La singularidad se despliega en su afán por las esencias, que seguramente en Guillén serían los arquetipos, las Ideas platónicas. De tal manera que utiliza verbos para no dejarse subsumir por el revolver:

\author{
Heme ante la realidad \\ Cara a cara. No me escondo, \\ Sigo en mis trece. Ni cedo \\ Ni cederé, siempre atónito. \\ (Cántico, p. 520)
}

Obsérvese cómo hay un doble proceso de proyecciones. Mientras que el verbo barajar se ve proyectado en singularidades más simples (proyecciones $\chi$ de la figura 1), el verbo ser aspira a quedar englobado en otras singularidades superiores (proyecciones $\theta$ de la figura 1). Pero, claró está, este doble juego no es simétrico. Para que este segundo proceso sea posible, para poder realizar las proyecciones, hay que estipular una singularidad, porque una singularidad de despliegue cero puede ser una proyección de cualquier verbo.

\title{
$V^{\prime}$
}

El poeta continúa su esfuerzo ¿por no aparentar arrogancia?: ésta sería una explicación psicologista. Nosotros diríamos que porque aún no ha expresado un verbo con el potencial suficiente como para poder absorber al barajar. Pues hay aún muchas fuerzas que actúan como parámetros suyos: volver, venir, quebrarse en disonancias (El análisis clásico hablaría del «Azar», de «La Historia»...). Y, mientras lo encuentra, su defensa no es la de un actante encerrado en una literaria torre de marfil, sino la de uno situado tras el frágil cristal de una ventana. Cristal que, sin embargo, le facilita la confiadora y estimulante visión de los astros. El mediador buscado se hace operativo a través de la «luz»:

\footnotetext{
¿Marfil? Cristal. A ningún

Rico refugio me acojo.

Mi defensa es el cristal

De una ventana que adoro.

(Cántico, p. 522)
}

Y los verbos con los que trata de «aguantar» la agresión del barajar son: sé, creo, respondo, palpo, dispongo, me dejo reducir, reconozco, sueño, me acojo, adoro. 
El héroe de Guillén defiende y afirma su lugar, su atractor, que trata una y otra vez de no dejarse arrastrar en ese barajar que ahora se presenta directamente como el mal: «fatalmente desordenando los modos...», Un atractor, el ser, que, también él, quiere acosar: «Lleve la dicha hasta el ímpetu / Con que yo también acoso»... Desde la pretensión de situarse en «el centro de la verdad», inicia su ataque. Así que ese minúsculo ser que es el poeta («No soy nadie, no soy nada, / pero soy») se pretende rodear de parámetros potentes (la luz, la hermosura, la verdad...) y, para poder desplegarse él mismo, los requiere cada vez más complejos, hasta poder desbaratar el barajar que ha originado ese «desbarajuste»: el mal. Confiado ya en sus armas - el ser (como singularidad) y la luz, la hermosura, la verdad... (como parámetros)—, el sitiado rompe, por fin, el asedio de su frágil protección, y se arroja con avidez hacia el mundo: se redondea, se perfecciona, para evitar la disolución de su ser.

Con la luz me perfecciono.

Yo soy merced a la hermosa

Revelación: este Globo».

(Cántico, p. 524)

Ahora bien, el poema no aclara de qué tipo sea el germen de esa singularidad para enfrentarse al Mundo, no utiliza ningún verbo que pueda dejar planteada la batalla; simplemente lanza ese grito de resistencia, de deseo de ser un atractor capaz de enfrentamiento. De ahí ese regusto a idealismo, a subjetivismo o voluntarismo, sin capacidad para proseguir la batalla y que, desde un punto de vista linguístico, deja insatisfecho a García Berrio. ${ }^{57}$

Hacemos hincapié en ese ser atónito que cara a cara, sin esconderse, admira el mundo: «A pesar de todo mi deseo de esencialización y ensimismamiento, de inclinarme hacia el punto de estabilización, no cedo a él y me muestro receptivo a las umbílicas parabólicas», diría Guillén (si se nos permitiese hacerlo hablar con nuestro lenguaje). El Mundo (las umbílicas parabólicas en nuestra terminología) se tiende, dócilmente, al asombro del ser, que, sin embargo, se proyecta (según la aplicación $\theta$ de la figura 1) hacia formas más complejas. El poeta parece haber llegado a una especie de pacto final: tras haber sentido la armonía del ser en los primeros Cántico —con la subsiguiente tendencia al

57 «Lo peor sobreviene, a mi juicio, cuando el poeta comienza a clausurar -para no repetirse sin duda - aquel sistema primero de evocación objetiva con sus peculiarísimos esquemas de visión sutilizada, geométrica y esquemática del objeto poético, y se confía a partir de 1945 al análisis metateórico de sus contenidos de visión. A partir de aquí Guillén olvida, lamentablemente, la sugerencia oblicua por la mención directa. Es el recurso que domina en el análisis diumo de «El diálogo» o en las tediosas refracciones lacustres de «Tiempo libre», desembocan en las tentaciones de monotonía de poemas como «Su persona», o el apologético colofón de «Cara a cara» $(\mathrm{GB}, 68)$. 
ensimismamiento- es hora ya de aceptar también sus despliegues, el conflicto entre atractores, origen de las morfologías, que, al menos fenomenológicamente, se presentan a menudo como lo negativo, la desarmonía, el caos o la confusión.

Hay dos peligros: perderse en medio del barajar o aniquilarse en el deseo de ser siempre en soledad, en la tentación de replegarse al yo sin el mundo. De ahí la tensión: entre un ser sin umbílicas enfrente y otro con umbílicas, el poeta elige éste último, consecuente con su deseo de admirar el mundo, ya presente en el primer Cántico. Ahora se dice capaz de soportar hasta el mundo de la Historia, de la Tempestad.

El ideal ser-en-el-mundo del héroe guilleniano sitúa, pues, a éste, justo en la cuerda floja entre el peligro de ser barajado y el de verse aniquilado en el ser. Su posición, en caso de peligro, habrá de ser en adelante tangente al ser, fuente nutricia, lugar de acogimiento, pero sin ceder, sin dejarse atrapar por él: porque fuera le llama el mundo, la Naturaleza: y si no hay luz, si hay niebla o tormenta y peligra su ser uno-y-distinto-en-el-mundo, al fin volverá la luz, o la pondrá él. Se arroja, avanza... y cuando sea preciso se replegará estratégicamente a la tangente con el ser (esencia, verdad, bien, belleza, luz, silencio, paz...). Justo en la tangente: hundiendo sus raíces en él, pero creciendo hacia la luz.

El final es indudablemente optimista: con una reafirmación de fe en el futuro, confianza en el yo y su luz y en la luz de fuera, frente a cualquier amenaza de tormenta:

\author{
Mientras se agrandan los ojos \\ Admirando \\ cómo el mundo \\ Se tiende fresco al asombro. \\ (Cántico, 524)
}

El héroe de Guillén no cede a la presión de la tormenta, al barajar de los cielos; no se abandona a la tentadora presión del ser.

\title{
CONCLUSIONES:
}

¿Hemos logrado nuestro propósito? ¿Hemos conseguido mostrar que el análisis inspirado en Thom aporta elementos de interés para la mejor comprensión de un poema?

Seguramente la pregunta no está bien formulada, pues esto dependerá de la mayor o menor expectativa que se tenga respecto de los formalismos. Lo que pretendemos decir es que la TC ofrece a la lingüística un «nuevo espíritu», si se nos permite este modo de hablar. $\mathrm{Y}$ sin querer extrapolar la comparación: cuando Galileo instaba a mirar por el telescopio a jesuitas o dominicos, éstos no «veían» la luna más nítidamente que a simple vista e incluso se negaban a mirar 
por ese «diabólico» artefacto. Lo que quería mostrar Galileo era una nueva forma de «ver» los cielos, y la tierra. La teoría de las catåstrofes de Thom nos insinúa una nueva forma de tratar el lenguaje.

$Y$ no hay en este modelo nada parecido a un mecanismo, a un molde al que todo lenguaje haya de plegarse, sino que, como en el poema Cara a cara, la selección y disposición de los verbos por parte del poeta, del escritor, del hablante están siempre contextualizadas por la teoría semántica y no por cualquier clase de contexto pragmático. Sabemos que una buena parte del pensamiento actual está presidido por la idea del significado como uso (Wittgenstein). Pero, sin perjuicio de su fertilidad en determinadas ocasiones, no podemos aceptar que la elección de los verbos sea puramente pragmática. Hay unos constreñimientos [contraintes] semánticos que la teoría de Thom nos permite empezar a comprender, constreñimientos que proceden de la representación del espacio exterior y de los procesos espacio-temporales, estudiados en nuestro artículo con referencia a los verbos. Como cualquier temprana aplicación de una teoría, nuestro ensayo requiere la mejor comprensión por parte de sus receptores. Esperamos poder continuar explorando otras posibilidades de la TC de cara al análisis de textos, como nombres, adjetivos y adverbios. 